This item was submitted to Loughborough's Research Repository by the author.

Items in Figshare are protected by copyright, with all rights reserved, unless otherwise indicated.

\title{
Fabrication of three-dimensional wavy single chamber solid oxide fuel cell by in situ observation of curvature evolution
}

PLEASE CITE THE PUBLISHED VERSION

http://dx.doi.org/10.1111/jace.14090

\section{PUBLISHER}

Wiley / @ American Ceramic Society

\section{VERSION}

NA (Not Applicable or Unknown)

\section{PUBLISHER STATEMENT}

This work is made available according to the conditions of the Creative Commons Attribution-NonCommercialNoDerivatives 4.0 International (CC BY-NC-ND 4.0) licence. Full details of this licence are available at: https://creativecommons.org/licenses/by-nc-nd/4.0/

\section{LICENCE}

CC BY-NC-ND 4.0

\section{REPOSITORY RECORD}

Choi, Indae, Manoj Prasanna Ranaweera, and Jung-Sik Kim. 2015. "Fabrication of Three-dimensional Wavy Single Chamber Solid Oxide Fuel Cell by in Situ Observation of Curvature Evolution”. figshare. https://hdl.handle.net/2134/17662. 


\section{journal}

\section{Fabrication of Three-Dimensional Wavy Single Chamber Solid Oxide Fuel Cell by In Situ Observation of Curvature Evolution}

\begin{tabular}{|r|l|}
\hline Journal: & Journal of the American Ceramic Society \\
\hline Manuscript ID & JACERS-36407.R3 \\
\hline Manuscript Type: & Article \\
\hline Complete List of Authors: & $\begin{array}{l}\text { Choi, Indae; Loughborough University, Aero \& Auto Engineering } \\
\text { Ranaweera, Manoj; Loughborough University, Aero \& Auto Engineering } \\
\text { Kim, Jung-Sik; Loughborough University, Aero \& Auto Engineering }\end{array}$ \\
\hline Keywords: & solid oxide fuel cell, sinter/sintering \\
\hline &
\end{tabular}

SCHOLARONE ${ }^{m}$

Manuscripts 
Fabrication of Three-Dimensional Wavy Single Chamber Solid Oxide Fuel Cell by In Situ Observation of Curvature Evolution

Indae Choi, Manoj Ranaweera, Jung-Sik Kim*

Dept. of Aeronautical \& Automotive Eng., Loughborough University, LE11 3TU, United Kingdom

\begin{abstract}
This study presents a fabrication process via experimental observations for curved porous multi-layer structures with a single step, co-sintering operation. Active monitoring the shrinkage behaviour of each porous layer during the co-sintering process leads to minimise mismatched stresses along with avoidance of severe warping and cracking. During co-sintering, in-plane stresses are developed in each layer due to differing shrinkage behaviours between layers. Analysis of curvature evolution using in-situ monitoring of the structure was performed in the design of a curved multi-layer structure via the co-sintering process. Materials used are NiO/CGO for anode; CGO for electrolyte; and LSCF for cathode. These materials are tape-casted with $20 \mu \mathrm{m}$ thickness and stacked to form bi- and triple-layer structures by hot pressing. Bi-layers, consisting of NiO/CGO-CGO and CGO-LSCF, were co-sintered up to $1200^{\circ} \mathrm{C}$. The maximum sintering mismatched stress was calculated at the interface of bi-layer structure. In-situ observation, to monitor the shrinkage of each material and the curvature evolution of the bi- and triple-layer structures, was performed using a long focus microscope (Infinity K-2). Thereby, viscosity, shrinkage rate of each material and curvature rate were calculated to determine the mismatched stresses. The monitored results contributed to development of novel design of curved 3D multi-layer structures during co-sintering.
\end{abstract}

1. Introduction

Co-sintering process of multi-layer structures has benefits regarding time, manufacturing effort and energy savings, and so has attracted increasing attention in a variety of research fields, including SOFCs (Solid Oxide Fuel Cells) [1-3]. In conventional fabrication of SOFCs [4-8], co-sintering has been usually applied to bi-layer structures, consisting of anode and electrolyte layer, as similar sintering behaviour of each layer prevents development of any defects such as warping, cracking and 
delamination during the process. In the process, mismatched sintering behaviour induces stresses that lead to self-developed curvature. The induced stresses developed due to the mismatched sintering behaviour in a bi-layer structure are maximised at the structure's interface and they often cause microstructure changes and/or undesired third phase formation across the structure's interface. In order to avoid the undesired curvature evolution during the co-sintering process, many researchers have restricted in their material selections, only choosing materials with similar sintering behaviour, or have placed an additional weight on the sintering layers that will suppress the curvature developments. Error! Reference source not found.. The latter method presents difficulties to practically determine the necessary weight in order to complete a crack-free sintering process. The weight is a dependant factor in the viscosity of the sintering material, and the viscosity is a function of the sintering temperature profile, where the sintering temperature profile is a function of time. Therefore the adequate weight for suppressing method for effective crack-free co-sintering is not fixed, but varies throughout the sintering process. Hence, determining the correct weight is not practically a straightforward method, but often requires a number of iterative trials.

During co-sintering, in-situ monitoring method is used to investigate sintering behaviour of each material and curvature evolution of multi-layer structures. Each layer is analysed with respect to its sintering behaviour via conducting free and vertical sintering experiments. The key factors that govern the sintering behaviour, such as viscosity, shrinkage rate of each material, and curvature rate, are investigated to determine how they affect the curvature evolution of the multi-layer structures during the co-sintering process. In addition, 3D deformation process from initially flat laminated structures is demonstrated to obtain a wavy structure. This enables fabrication process of wavy type SOFC through a single fabrication process; a triple-layer co-sintering process.

Unlike the conventional SOFCs, the SC-SOFCs (Single Chamber-Solid Oxide Fuel Cells) consist of only one gas compartment containing a gas mixture of fuel and oxygen [11-13]. The use of gas mixture in the SC-SOFCs has various advantages. It is not necessary to secure gas tight sealing by exposure of all components in the same gas condition. In addition, since the cell is located in one gas compartment, complex gas manifolds and flow structures for gas supply can be eliminated, making it possible to create a simpler and more compact cell. It also becomes acceptable for the electrolyte layers to have pores or small pore-like cracks on them. However, these advantages are cancelled out with a major drawback; the SC-SOFC shows poor catalytic selectivity for chemical reaction at TPB 
(Triple Phase Boundary), contributing to lower fuel utilisation and so dropping the cell's overall efficiency.

It has been suggested that a wavy type SC-SOFC can cope with the above issues, as the cell will naturally form a higher effective electrochemical reaction area in order to enhance its overall efficiency. The study employs a wavy cell that has $7.1 \%$ higher effective cell area for a given area defined by the cell perimeter (geometric projected area). The advantages of the wavy cell are: mechanical robustness derived from the shape which can absorb a level of shock, and improvement of the active cell area contributing to higher performance, compared with planar type SC-SOFCs of the same diameter. Furthermore, as the cell design is going to have a porous structure with the gases flowing through, proposed by Riess [14], the cell has more reaction sites as well. Despite the potential advantages of wavy type SC-SOFC, only simulation approaches have been carried out $[15,16]$, but experimental attempts were successful, due to the mismatch of sintering behaviour of each layer.

This study suggests a novel single fabrication process to form a wavy type SC-SOFC by exploiting the result of bi-layer co-sintering observation and the deflection-free co-sintering conditions that retains the initial green body's shape upon completion of the sintering process. The shape might change during the process, but will retain the initial shape by the time the process finishes. Deflectionfree condition of the triple-layer structure during the co-sintering process without taking advantage of weight suppressing method is investigated by a comparison of an observed curvature via in-situ monitoring to a simulated curvature that is predicted from the curvatures of bi-layer co-sintering.

\section{Experimental procedure}

\subsection{Curvature evolution}

The strategy applied in the present study was to measure the shrinkage rate and the uniaxial viscosity of the specimens by monitoring the resulting curvature development of the sintering layers. Therefore it was first necessary to establish the free sintering and vertical sintering using single layer specimens. As shown in Fig 1a, for shrinkage measurement in free sintering, a free standing specimen was cut to rectangle and rest on a specimen support. An alumina block was machined into the support shape for the arrangement. This support was specifically designed to hold the specimen 
upright, whilst the top width of specimen was monitored during the sintering experiment. The set-up was heated up to $750^{\circ} \mathrm{C}$ with a ramping rate of $1^{\circ} \mathrm{C} / \mathrm{min}$ for a debinding process, and then continually heated up to $1200^{\circ} \mathrm{C}$ by $3^{\circ} \mathrm{C} / \mathrm{min}$, and held for $15 \mathrm{~min}$ at the temperature. After the holding, it was cooled down to room temperature by $3^{\circ} \mathrm{C} / \mathrm{min}$. During the sintering process, shrinkage measurement along the horizontal direction of the sample was carried out by long-distance microscope, Infinity-K2. In vertical sintering T-shaped samples were prepared, Fig 1c. Specimens have height to width ratio 3 or greater to ensure that the shrinkage in vertical direction $(L)$ is much greater than that in width direction (W), so accurate measurement of vertical shrinkage is obtainable via the image readings. The shrinkage behaviours along the vertical direction were only investigated in this case. These results were used for calculation of the uniaxial viscosities from difference of shrinkage rate between free and vertical sintering.

Then, each layer was cumulated to a stack and hot pressed with a various lamination pressure and temperatures for 5 min to build multi-layer structures shown in Fig 2, and $40^{\circ} \mathrm{C}$ at 45 bar was selected for the multi-layer structure fabrications. Then, in-situ monitoring of curvature evolution during the co-sintering of these multi-layer structures was conducted via Infinity K-2. The image of curvature evolution of the samples was captured at every $25^{\circ} \mathrm{C}$ by the Infinity $\mathrm{K}-2$, and the radius of the curvature was calculated using the equation A.1 and the Fig A1 in the Appendix A. For curvature evolution of the structures with various thickness ratios, bi-layer structures, consisting of NiO/CGOCGO and CGO-LSCF, and triple-layer structures, consisting of NiO/CGO-CGO-LSCF, were prepared. The curvature evolution of the specimens were only analysed at a temperature range between $900^{\circ} \mathrm{C}$ and $1200^{\circ} \mathrm{C}$ for sintering behaviour investigation. Based on the materials' uniaxial viscosity and curvature evolution monitoring result, particularly monitoring of the bi-layer structures, curvature evolution of a triple-layer structure was predicted. The predicted curvature evolutions of triple-layer structures were obtained by calculating the average of the two curvatures from the given bi-layer structures. The predicted curvatures were then compared with measured curvatures from the experimental observations. Finally, deflection-free sintering condition was determined by understanding the curvature evolutions of bi- and triple-layer structures via in-situ curvature monitoring. The deflection-free sintering condition was then applied for a fabrication of a 3D triplelayer structure. 


\subsection{Specimens}

For the study, the materials used are NiO/CGO for anode; CGO for electrolyte; and LSCF for cathode, shown in Table 1, and they are in line with the most recent trends in SOFC research. Tapecasting process of these materials was carried out with support of Maryland tape-casting company. The slurry compositions are shown in Table 2 . The thickness of each green layer was $20 \pm 1 \mu \mathrm{m}$ and several layers were laminated by a hot pressing method at $40^{\circ} \mathrm{C}, 45$ bar for $5 \mathrm{~min}$, to form multi-layer structures. Specimens with various thicknesses and various thickness ratios were prepared by stacking different number of layers for each fuel cell component. The microstructures of the specimens were examined by SEM (Hitachi TM3000).

\subsection{Thickness ratio}

In elastic-viscous analogy [17-21], the Young's modulus, the Poisson's ratio and shrinkage can be replaced with the uniaxial viscosity, the viscous Poisson's ratio and shrinkage rate, respectively. A uniaxial viscosity of the material can be measured using the vertical sintering method proposed by Cologna et al. Error! Reference source not found. and see equation 1 below. In this method, during the vertical sintering process with a hanging sample, the specimen's own weight acts as an applied stress contributing to the shrinkage behaviour. It has been shown that the stress generated is not sufficient to affect the specimen's microstructure changes during the sintering process and a porous body undergoing densification can be treated as linearly viscous at stresses below $1 \mathrm{MPa}$. Under the slight uniaxial tension or uniaxial compression, the creep rates of these materials are the same [23]. As the very low applied load by its own weight does not cause any appreciable difference in the strain rates between free and vertical sintering process, this method has a limit to measure the viscosity at high density.

$$
\eta=\frac{\rho g L}{2\left(\dot{\varepsilon}_{v}-\dot{\varepsilon}_{f}\right)}
$$


where $L$ is the specimen length, $\rho$ the material density, $g$ the gravity, $\dot{\varepsilon_{v}}$ the shrinkage rate in vertical sintering and $\dot{\varepsilon}_{f}$ the shrinkage rate in free sintering. The difference of shrinkage rate between free sintering and vertical sintering is the main influential factor to determine the uniaxial viscosity of the material during the sintering process.

In a bi-layer structure based on Cai's model [24, 25], curvature evolution comes from sintering mismatched stress between layers during the co-sintering process. It is shown that the maximum stress in upper layer $\left(\sigma_{1}^{M a x}\right)$ is at the interface and can be calculated by:

$$
\sigma_{1}{ }^{\text {Max }}=\left[\frac{m^{2} n(4 m+3)+1}{m^{4} n^{2}+2 m n\left(2 m^{2}+3 m+2\right)+1}\right] \widehat{\sigma_{1}}
$$

where $m$ is the thickness ratio, $n$ the viscosity ratio, and $\widehat{\sigma_{1}}$ viscous mismatched stress of upper layer. In Cai's model, the theoretical normalised curvature rate, $\dot{k}$ (thickness over radius of curvature), from different shrinkage behaviour during the co-sintering process can be given by:

$$
\dot{k}=\left[\frac{6(m+1)^{2} m n}{m^{4} n^{2}+2 m n\left(2 m^{2}+3 m+2\right)+1}\right] \Delta \dot{\varepsilon}
$$

where $\Delta \dot{\varepsilon}$ is the difference of the shrinkage rate between layers. It is shown that if properties of the materials are similar in bi-layer structure, the influential factor that determines the curvature evolution of the bi-layer structure during the co-sintering process is the thickness ratio.

\section{Results and Discussion}

3.1 Uniaxial viscosity

The equivalent shrinkage of materials and shrinkage difference, measured by in-situ observation, are shown in Fig 3; 3a for NiO/CGO, 3b for CGO, and 3c for LSCF. The shrinkage rate of free 
sintering in all materials was faster than that of vertical sintering. On the basis of shrinkage rate of CGO material, Fig $3 d$ shows the shrinkage rate difference with NiO/CGO and LSCF during the sintering process. There was a small difference in shrinkage in the NiO/CGO-CGO specimen due to both materials' similar properties, whereas there were significant larger differences in the CGO-LSCF specimen. It was expected that higher shrinkage of LSCF would lead the curvature evolution of biand triple-layer structures at the early stage of co-sintering. In vertical shrinkage measurements, the sample was subject to low tensile stress generated by its own weight $[22,26]$. After the sintering process at $1200{ }^{\circ} \mathrm{C}$, the relative densities of the samples were $61 \% \sim 65 \%$. The density agreed well with SEM inspection as shown in Fig 4. It has been well known that the sintering temperature of LSCF is lower than that of CGO-based materials under the same conditions such as initial particle size, green density and heating rate. In the shrinkage rate of LSCF between free and vertical sintering, the difference was close to zero at $1200^{\circ} \mathrm{C}$. This means that the viscosity at higher density over $1200^{\circ} \mathrm{C}$ cannot be calculated by the vertical sintering method, as the very low tensile stress from its own weight does not cause a remarkable difference in the shrinkage rate. As shown in Fig 5 , the uniaxial viscosities of each material, as functions of relative density and difference of shrinkage rates between free and vertical sintering as proposed by Cologna, were calculated using Eq. (1). At low temperature, the viscosity was high, then decreased with increasing temperature in the early stage of the sintering process. When the temperature reached to $1050^{\circ} \mathrm{C}$, the viscosity increased again as the density of the sintering layer has increased. These values were used to investigate the curvature evolution of biand triple-layer structures during the co-sintering process.

3.2 Curvature evolution of multilayer structures

Experimentally, during the co-sintering of bi-layer structures, the curvature evolution of structures has occurred due to the different shrinkage behaviour and the viscosity variations between the two layers. The results of curvature observations of bi-layer structures, whilst the total thickness varies, but the same thickness ratio was maintained, are shown in Fig 6. In-situ observation, to monitor the shrinkage of each material and the curvature evolution of the bi-layers, was carried out using a long focus microscope at specific temperatures up to $1200^{\circ} \mathrm{C}$. The thickness of the bi-layer structures after the hot pressing was approximately $15 \%$ less than the sum of each green layer. When fabricating the 
multi-layer structures by the hot pressing process, microstructural rearrangement and anisotropy might have been induced into the structure during the process, contributing to different green density. A positive curvature (curves towards the bottom layer) was developed from $900^{\circ} \mathrm{C}$, when a bi-layer of $\mathrm{NiO} / \mathrm{CGO}$ (top)-CGO (bottom) was tested, Fig 6(a). After that, the curvature rate reduced while the maximum positive curvature was achieved at $1080^{\circ} \mathrm{C}-1180^{\circ} \mathrm{C}$. Then the curvature became negative as the bi-layer was curving towards top layer for the structure with 1:1 ratio. On the other hand, a bilayer of CGO (top)-LSCF (bottom), developed negative curvature in the early stage, then rapidly formed a positive curvature after reaching the maximum curvature at $1020^{\circ} \mathrm{C}-1120^{\circ} \mathrm{C}$, Fig 6 (b). In both experiments, it is seen that curvature evolution changed gradually towards CGO layer when temperature increases. This was because the highest shrinkage rate of the CGO layer during the later stage of sintering overwhelms the shrinkage rate of another layer. In addition, the peak point (maximum or minimum value) of each curvature was increased and shifted towards a higher temperature when overall thickness increases. It was attributed to the thinner structure in which the residual stress could be expressed easily through macro-deformation and the effect of gravity would be less than that of thicker structures, contributing to curvature evolution during the co-sintering process. The level of shrinkage mismatch of CGO-LSCF was higher than that of NiO/CGO-CGO, and so the curvature rate of CGO-LSCF was higher that cause quicker curvature developments as the temperature increases.

In the comparison of the normalised curvature rates between Cai's model and experimental results shown in Fig 7, it can be seen that the curvature rate of bi-layer structures showed similar trends (positive to negative rate for NiO/CGO-CGO and vice versa for CGO-LSCF). It also shows that total thickness as well as thickness ratio should be considered to predict the curvature evolution during cosintering. In the structures of NiO/CGO-CGO, Fig 7(a), higher shrinkage of the NiO/CGO layer leaded to increase curvature rate of the bi-layer structures up to $1050^{\circ} \mathrm{C}$, then decreased with increasing temperature. Likewise, in CGO-LSCF structures shown in Fig 7(b), LSCF layer leaded initial curvature rate, then it was overwhelmed by the sintering behaviour of CGO layer. As the total thickness of structure increased, maximum curvature rate was shifted to higher temperatures. It is noticeable that some level of discrepancy has developed between the theoretical approach using Cai's model and the experimental results by in-situ observation. Different curvature rates were observed for thicker samples of the same bi-layer material which had the same thickness ratio. This could be attributed to 
residual stresses at the interface of thicker structures being different from that of a thin structure, even using the same materials with the same thickness ratio. In addition, due to gravity effect with increasing thickness, the retardation of curvature evolution should be considered Error! Reference source not found.. Macro-scale deformation can be easily expressed in thin structure due to its low flexural rigidity, whereas thicker structures have higher tolerance against the deformation. This effect was not regarded in Cai's model. In the experimental approach, each factor might not be constant during co-sintering. For instance, when a curvature occurred, the thickness of the layer under compression might become relatively thicker than the layer under tension. Likewise, the difference of strain rate changed depending on curvature evolution state during the co-sintering of the bi-layer structure. Thus, three correlation factors, variable from 0.8 to 1.2 , were applied to Cai's data, shown in the equation B.1 in the Appendix B, to compare with experimental data. The details of the analysis are given in the Appendix B where possible influence of correlation factors is discussed. As a result, the curvature rate was increased when higher correlation factors were applied on thickness ratio and strain rate difference, shown in the Fig B1 in Appendix B. In summary, in the comparison with experimental results, the curvature rate of the structure consisting of thicker layers would be vulnerable to variation of thickness ratio and strain rate. In case of shift action to higher temperature, it depends on the strain rate mismatch between layers and the flexural rigidity of each layer (functions of viscosity, viscous Poisson's ratio and thickness).

Maximum sintering mismatched stress at the interface of bi-layer structures was calculated using Eq. (2), shown in Fig 8. In the structure of NiO/CGO-CGO, Fig 8(a), positive mismatched stress (tensile stress) occurred at the interface of upper layer (NiO/CGO) in the early stages of co-sintering and then reversed to become negative stress (compressive stress) later in the co-sintering process. Likewise, compressive stress was observed at the interface of upper layer (CGO) in the CGO-LSCF structure and then reversed to tensile stress with increasing temperature, shown in Fig 8(b). As macro-deformation of the structure with increasing thickness was reduced during co-sintering, stress variation at the interface was small compared with thin structure. During co-sintering the stress mismatch between layers of the bi-layer structures did not give rise to any significant defects such as cracking or delamination. It is generally known that the driving force of free sintering, called sintering stress, is greater than the sintering mismatched stresses occurred during the co-sintering process [29]. 
In the co-sintering of triple-layer structures, Fig 9 shows the curvature evolution of the triple-layer structures with the curvature prediction calculated from curvatures of bi-layer structures. For the digital image correlation and the curvature calculations, the captured digital images were processed by ImageJ programme. As the sintering behaviour of CGO layer in the triple-layer structures was influenced by both $\mathrm{NiO} / \mathrm{CGO}$ and LSCF layers at the same time, the mechanism to determine curvature evolution in triple-layer structures became more complicated. In Fig $9 b$ and $9 d$, it is shown that curvature behaviour, for which thinner layer is dominant for curvature evolution of the bi-layer structures, is identical to curvature evolution of triple-layer structures during co-sintering. As the flexural rigidity of triple-layer structures was higher than bi-layer structures, there was no drastic change of curvature evolution during co-sintering. From the experimental observations, the prediction of the triple-layer structures was feasible in the condition that there was no severe curvature evolution during the co-sintering of the bi-layer structures. In addition, the flexural rigidity of the structures should be regarded as one of the influential factors affecting curvature evolution of thicker structures, resulting in retardation of curvature change.

\subsection{Curved triple-layer structure from deflection-free co-sintering}

The shrinkage behaviour has been continuously monitored throughout this study and an attempt to control the behaviour in order to utilise it and promote a wavy shape has been sought. Consequently, among various conditions, a triple layer structure of thickness ratio 1:3:9 (anode, electrolyte and cathode respectively) was employed to facilitate this curvature evolution in the desired manner in order to fabricate a wavy triple-layer structure during co-sintering. The ratio indicates the number of layers used in the components, so anode has 1 layer $(20 \mu \mathrm{m})$, electrolyte has 3 layers $(60 \mu \mathrm{m})$ and cathode has 9 layers $(180 \mu \mathrm{m})$; the overall green body thickness of $260 \mu \mathrm{m}$. The curvature evolutions captured by using the optical method were shown in Fig 10. The negative curvature towards LSCF layer was dominant till around $1000^{\circ} \mathrm{C}$ where the layer shrank faster than CGO and NiO/CGO. The curvature was then decreased with increasing temperature due to the overwhelming sintering kinetics of $\mathrm{NiO} / \mathrm{CGO}$ and $\mathrm{CGO}$. After reaching deflection-free state at $1150^{\circ} \mathrm{C}$, positive curvature developed towards $\mathrm{NiO} / \mathrm{CGO}$ layer. Although there remained curvature evolution towards $\mathrm{NiO} / \mathrm{CGO}$ layer at the 
final temperature of the co-sintering process, it could be compensated by higher thermal expansion coefficient of LSCF during the cooling process. This experimental condition was applied to fabricate wavy structures from initially flat structures, shown in Fig 11. A planar green triple-layer structure is laid on supporting rods at room temperature, Fig 11(a). The structure could be deformed as precurved structures at $80^{\circ} \mathrm{C}$, Fig 11 (b), by structural flexibility due to binder softening. An optical image of the co-sintered wavy type SC-SOFC is shown in Fig 11(c). The comparison of microstructures in the planar and wavy type SC-SOFCs was examined using SEM and shown in Fig 11; (d) (f) for wavy structure and $(\mathrm{g})$ for SEM image for planar structure, and $(\mathrm{h}, \mathrm{i})$ at the interface of wavy structure. The sintered structure has a $175 \pm 2 \mu \mathrm{m}$ total thickness (16 $\mu \mathrm{m}$ for anode, $37 \mu \mathrm{m}$ for electrolyte, and $122 \mu \mathrm{m}$ for cathode). In addition, pore size of LSCF is larger than others. As it is well known that sintering temperature of cathode material is lower than that of anode or electrolyte material, LSCF with coarse green particle (Ave. particle size was $1 \mu \mathrm{m}$ ) was used to match the final porosity of each material after co-sintering. Based on the image of the planar cell $(\mathrm{g})$, the wavy cell has different porosity distribution $(d, f)$ and similar porosity distribution and microstructure $(e)$ at the same time. It was attributed that curved structure affected microstructural rearrangement and sintering stresses at the interfaces during co-sintering. Fig 12 shows XRD results with single material and bi-layer structures. After the co-sintering of the triple-layer structure, the structure maintained its initial shape and showed that there was no third-phase material formation at the interfaces during the co-sintering process.

\section{Conclusions}

In-situ observation method was applied to investigate shrinkage behaviour of each material as well as curvature evolution of bi- and triple-layer structures. Uniaxial viscosity of materials was measured by free and vertical sintering method. The results of curvature evolution were compared with theoretical approach using Cai's model. In this study, thickness conditions of bi- and triple-layer structures acted as influential factors to affect curvature evolution during the co-sintering of multi-layer structures. The experimental results were different to Cai's model because as the total thickness 
increased, the curvature evolution might be retarded due to different residual stresses, flexural rigidity and gravity effect against curvature evolution. The deflection-free condition was investigated and utilised for fabrication of a curved triple-layer structure during co-sintering. The wavy triple-layer structure was fabricated without any defects such as cracking, distortion or third phase material formation. As the structure has $7.1 \%$ higher effective electrochemical reaction area compared to the planar structure in the same diameter, it is expected to make the use of porous filter, sensor, and fuel cell system. The suggested method opens the prospect of designing a new co-sintering process for multiple-layered structures in 3D shape.

\section{Acknowledgements}

The authors appreciate partial financial support from the India-UK Collaborative Research Initiative in Fuel Cells project on "Modelling Accelerated Ageing and Degradation of Solid Oxide Fuel Cells (EP/1037059/1)".

\section{Appendix A}

Curvature measurement

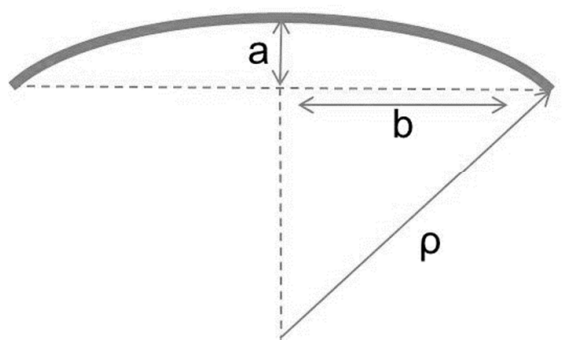

Fig A1 Schematic of curvature measurement

$$
\rho=\frac{a^{2}+b^{2}}{2 a}
$$

Appendix B

Influence of correlation factors 
The equation of normalised curvature rate used in Cai's model is functions of thickness ratio (m), viscosity ratio $(n)$, and strain rate difference $(\Delta \dot{\varepsilon})$. Using three correlation factors, $\alpha, \beta, \gamma$ with a range of $0.8 \sim 1.2$, the influence of each factor can be investigated on the determination of normalised curvature rate, so as to compare experimental data. Three corresponding factors in the equation 3 is now replaced with $\alpha \mathrm{m}, \beta \mathrm{n}$, and $\gamma \Delta \dot{\varepsilon}$. The modified equation is

$$
\dot{k}=\left[\frac{6(\alpha m+1)^{2} \alpha m \beta n}{(\alpha m)^{4}(\beta n)^{2}+2 \alpha m \beta n\left(2(\alpha m)^{2}+3 \alpha m+2\right)+1}\right] \gamma \Delta \dot{\varepsilon}
$$

The effect of correlation factors is shown in Fig. B1 along with experimental curvature plots. The influence of a correlation factor to the thickness ratio is investigated first. The correlation factor $\alpha$ is variable from 0.8 to 1.2 with a 0.1 increment whilst the $\beta, \gamma$ are fixed as 1 . A comparison to the $\mathrm{NiO} / \mathrm{CGO}-\mathrm{CGO}$ bi-layer structures with their variable total thicknesses $(1 \sim 5)$ is given in Fig B1-a. The factor on thickness ratio influences to increase the maximum normalised curvature rate. But, the factor affects little to the behaviour of curvature rate after reaching to the maximum point. Similarly, a variable $\beta$ is calculated and shown in Fig B1-b. The variable $\beta$ has brought only little impact to the curvatures. When the $\gamma$ is applied with the same variable range, the calculated curvatures show not only the increase of the maximum rate, but also faster curvature rate in Fig B1-c. Calculations when the three factors are all variable within the given range at the same time are shown in Fig B1-d; the plots are following the experimentally observed curvature behaviours with relative closeness as compared to the other cases shown in $\mathrm{a} \sim \mathrm{c}$, though the shift of graphs with increasing total thickness are not well agreed. In summary, the influence of correlation factors shows that normalised curvature evolutions in experimental data are sensitive to each individual factor which can be variable depending on curvature evolution state, whereas they are all constants in Cai's model. 


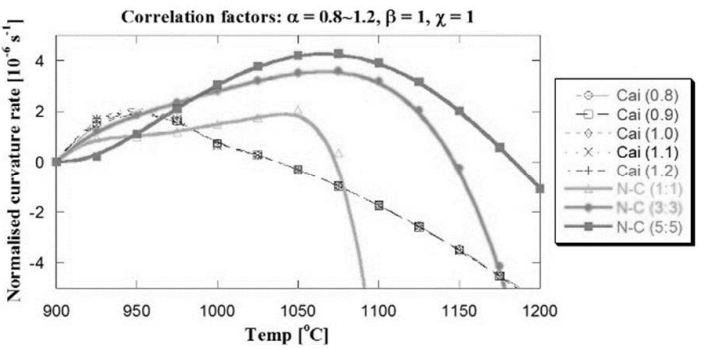

(a)

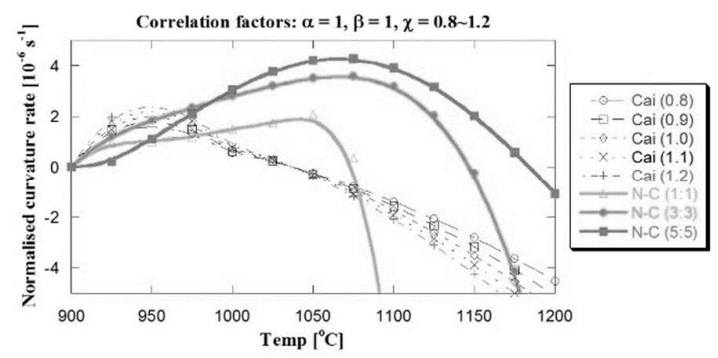

(c)

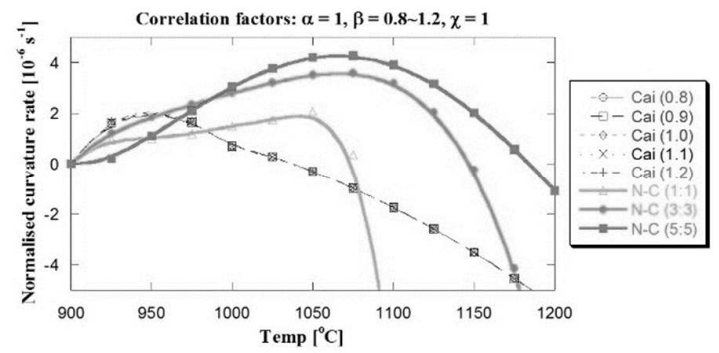

(b)

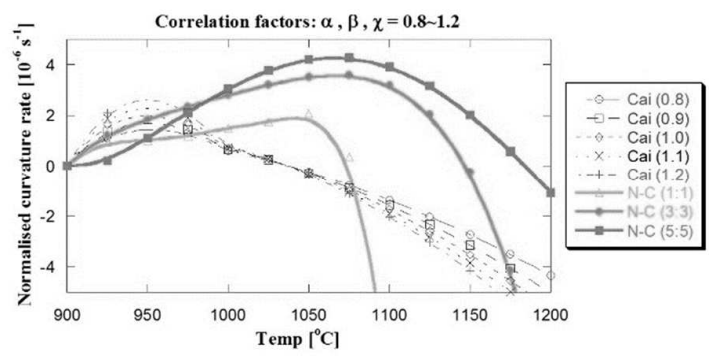

(d)

Fig B1 Comparisons of normalised curvature rate between experimentally observed results and the calculated results applying correlation factors to the Cai's model.

References

[1] Y. Imanaka, "Multilayered low temperature cofired ceramics (LTCC) technology" Springer (2005).

[2] D. J. Green, O. Guillon and J. Rödel, "Constrained sintering: A delicate balance of scales," Journal of the European Ceramic Society, 28 [7] 1451-1466 (2008).

[3] A. Mohanram, G. L. Messing and D. J. Green, "Densification and Sintering Viscosity of Low-Temperature Co-Fired Ceramics," J Am Ceram Soc, 88 [10] 2681-2689 (2005).

[4] D. Stöver, H. P. Buchkremer and S. Uhlenbruck, "Processing and properties of the ceramic conductive multilayer device solid oxide fuel cell (SOFC)," Ceram. Int., 30 [7] 1107-1113 (2004).

[5] H. Kishi, Y. Mizuno and H. Chazono, "Base-metal electrode-multilayer ceramic capacitors: past, present and future perspectives," Japanese journal of applied physics, 42 [part 1] 1-15 (2003). 
[6] C. F. Chou, R. Changrani, P. Roberts, D. Sadler, J. Burdon, F. Zenhausern, S. Lin, A. Mulholland, N. Swami and R. Terbrueggen, "A miniaturized cyclic PCR device-modeling and experiments," Microelectronic Engineering, 61-62 [0] 921-925 (2002).

[7] P. Holtappels and C. Bagger, "Fabrication and performance of advanced multi-layer SOFC cathodes," Journal of the European Ceramic Society, 22 [1] 41-48 (2002).

[8] E. Ivers-Tiffee, A. Weber and D. Herbstritt, "Materials and technologies for SOFC-components," Journal of the European Ceramic Society, 21 [10] 1805-1811 (2001).

[9] S. H. Lee, G. L. Messing and D. J. Green, "Warpage evolution of screen printed multilayer ceramics during co-firing," Key Eng Mat, 264, 321-330 (2004).

[10]S. Lee, G. L. Messing and M. Awano, "Sintering Arches for Cosintering Camber-Free SOFC Multilayers," J Am Ceram Soc, 91 [2] 421-427 (2008).

[11]T. W. Napporn, X. Jacques-Bédard, F. Morin and M. Meunier, "Operating conditions of a singlechamber SOFC," J. Electrochem. Soc., 151 [12] A2088-A2094 (2004).

[12]Z. Shao, S. M. Haile, J. Ahn, P. D. Ronney, Z. Zhan and S. A. Barnett, "A thermally selfsustained micro solid-oxide fuel-cell stack with high power density," Nature, 435 [7043] 795-798 (2005).

[13]T. W. Napporn, F. Morin and M. Meunier, "Evaluation of the actual working temperature of a single-chamber SOFC," Electrochemical and solid-state letters, 7 [3] A60-A62 (2004).

[14] I. Riess, "On the single chamber solid oxide fuel cells," J. Power Sources, 175 [1] 325-337 (2008).

[15]J. Hwang, C. Chen and D. Lai, "Computational analysis of species transport and electrochemical characteristics of a MOLB-type SOFC," J. Power Sources, 140 [2] 235-242 (2005).

[16] M. Stygar, T. Brylewski and M. Rękas, "Effects of changes in MOLB-type SOFC cell geometry on temperature distribution and heat transfer rate in interconnects," Int. J. Heat Mass Transfer, 55 [15] 4421-4426 (2012).

[17] R. K. Bordia and G. W. Scherer, "On constrained sintering—I. Constitutive model for a sintering body," Acta metallurgica, 36 [9] 2393-2397 (1988).

[18] R. K. Bordia, R. Zuo, O. Guillon, S. M. Salamone and J. Rödel, "Anisotropic constitutive laws for sintering bodies," Acta materialia, 54 [1] 111-118 (2006).

[19]A. Atkinson, J.-S. Kim, R. Rudkin, S. Taub and X. Wang, "Stress induced by constrained sintering of 3YSZ films measured by substrate creep," J Am Ceram Soc, 94 [3] 717-724 (2011). 
[20] J.-S. Kim, R. A. Rudkin, X. Wang and A. Atkinson, "Constrained sintering kinetics of 3YSZ films," Journal of the European Ceramic Society, 31 [13] 2231-2239 (2011).

[21]X. Wang, J.-S. Kim and A. Atkinson, "Constrained sintering of 8 mol\% Y2O3 stabilised zirconia films," Journal of the European Ceramic Society, 32 [16] 4121-4128 (2012)

[22] M. Cologna and V. M. Sglavo, "Vertical sintering to measure the uniaxial viscosity of thin ceramic layers," Acta Materialia, 58 [17] 5558-5564 (2010).

[23] S. Lee, G. L. Messing and D. J. Green, 'Bending Creep Test to Measure the Viscosity of Porous Materials during Sintering,' J Am Ceram Soc, 86 [6] 877-882 (2003).

[24]P. Z. Cai, D. J. Green and G. L. Messing, "Constrained densification of alumina/zirconia hybrid laminates, I: experimental observations of processing defects," J Am Ceram Soc, 80 [8] 19291939 (1997).

[25]P. Z. Cai, D. J. Green and G. L. Messing, "Constrained densification of alumina/zirconia hybrid laminates, II: viscoelastic stress computation," J Am Ceram Soc, 80 [8] 1940-1948 (1997).

[26] M. Cologna, V. M. Sglavo and M. Bertoldi, "Sintering and Deformation of Solid Oxide Fuel Cells Produced by Sequential Tape Casting," International Journal of Applied Ceramic Technology, 7 [6] 803-813 (2010).

[27]W. Li and J. J. Lannutti, 'Curvature evolution in LTCC tapes and laminates,' Components and Packaging Technologies, IEEE Transactions on, 28 [1] 149-156 (2005).

[28]D. Ni, V. Esposito, C. G. Schmidt, T. T. Molla, K. B. Andersen, A. Kaiser, S. Ramousse and N. Pryds, "Camber Evolution and Stress Development of Porous Ceramic Bilayers During Co-Firing," J Am Ceram Soc, 96 [3] 972-978 (2013).

[29]M. Chiang, J. Jean and S. Lin, "Effects of green density difference on camber development during the cofiring of a bi-layer glass-based dielectric laminate," Mater. Chem. Phys., 128 [3] 413-417 (2011). 
Figure Caption List

Fig 1 Schematic of experimental set-up; (a) in-situ observation, (b) sample for free sintering, and (c) sample for vertical sintering

Fig 2 Multi-layer structures by hot pressing method under various lamination pressures (unit: bar)

Fig 3 Shrinkage and shrinkage rate difference; (a) NiO/CGO, (b) CGO, (c) LSCF, and (d) shrinkage rate difference

Fig 4 SEM images of each layer after the sintering process at $1200^{\circ} \mathrm{C}$

Fig 5 Uniaxial viscosity: (a) NiO/CGO, (b) CGO, and (c) LSCF

Fig 6 Normalised curvature of bi-layer structure: (a) NiO/CGO-CGO, (b) CGO-LSCF

Fig 7 Normalised curvature rate; (a) NiO/CGO-CGO, (b) CGO-LSCF

Fig 8 Sintering mismatch stress of bi-layer structure: (a) NiO/CGO-CGO, (b) CGO-LSCF

Fig 9 Curvature evolution of the triple-layer structures and prediction based on bi-layer structures

Fig 10 Experimental observation of curvature evolution in the triple-layer structure, consisting of 1 layer for NiO/CGO (bottom), 3 layers for CGO, and 9 layers for LSCF (top).

Fig 11 A wavy SC-SOFC fabrication process (a) (c), and SEM images; (a) initial set-up at $20^{\circ} \mathrm{C}$, (b) wavy shaping at $80^{\circ} \mathrm{C}$ during binder softening, (c) a wavy SC-SOFC after co-sintering, (d) (f) cross sections of the wavy structure, (g) cross section of a planar structure, (h, i) at interfaces of the wavy structure.

Fig $12 \mathrm{XRD}$ result for third-phase formation of the wavy structure during co-sintering;

(a) NiO/CGO, (b) CGO, (c) LSCF, (d) NiO/CGO-CGO, and (e) CGO-LSCF 
Table 1 Specification of materials

\begin{tabular}{|c|c|c|c|}
\hline Name & Composition & $\mathbf{d}_{50}(\boldsymbol{\mu m})$ & $\mathbf{S}_{\mathrm{BET}}\left(\mathbf{m}^{2} \mathbf{g}^{-1}\right)$ \\
\hline NiO/CGO & $\begin{array}{c}60 \mathrm{wt} \% \mathrm{NiO} / 40 \mathrm{wt} \% \mathrm{CGO} \\
(\text { NexTech Material Ltd })\end{array}$ & 0.3 & $4-8$ \\
\hline CGO & $\begin{array}{c}\mathrm{Ce}_{0.8} \mathrm{Gd}_{0.2} \mathrm{O}_{2-\delta} \\
(\text { NexTech Material Ltd })\end{array}$ & 0.3 & $5-8$ \\
\hline LSCF & $\begin{array}{c}\mathrm{La}_{0.6} \mathrm{Sr}_{0.4} \mathrm{Co}_{0.2} \mathrm{Fe}_{0.8} \mathrm{O}_{3-\delta} \\
(\mathrm{NexTech} \text { Material Ltd })\end{array}$ & 1.0 & $4-8$ \\
\hline
\end{tabular}


Table 2 Slurry compositions for tape-casting

\begin{tabular}{|c|c|c|c|c|c|}
\hline \multicolumn{2}{|l|}{ Anode layer } & \multicolumn{2}{|l|}{ Electrolyte layer } & \multicolumn{2}{|l|}{ Cathode layer } \\
\hline Materials & $w t \%$ & Materials & $w t \%$ & Materials & $w t \%$ \\
\hline $\begin{array}{c}\text { Nickel Oxide-GDC } \\
\text { (60 wt\%NiO- } \\
40 w t \% G D C)\end{array}$ & 63.3 & $\begin{array}{l}\text { Gadolinium-Doped } \\
\text { Ceria }(20 \% \text { Gd) }\end{array}$ & 62.13 & LSCF & 62.36 \\
\hline Xylenes & 14.22 & Xylenes & 14.61 & Xylenes & 12.74 \\
\hline Ethyl Alcohol (95\%) & 14.22 & Ethyl Alcohol (95\%) & 14.61 & Ethyl Alcohol (95\%) & 12.74 \\
\hline Polyvinyl Butyral, B-98 & 4.11 & Polyvinyl Butyral, B-98 & 4.35 & Polyvinyl Butyral, B-98 & 6.24 \\
\hline $\begin{array}{l}\text { Triethyleneglycol bis(2- } \\
\text { ethyl hexanoate) }\end{array}$ & 1.44 & $\begin{array}{l}\text { Triethyleneglycol bis(2- } \\
\text { ethyl hexanoate) }\end{array}$ & 1.53 & Polyalkylene Glycol & 3.12 \\
\hline Polyalkylene Glycol & 1.44 & Polyalkylene Glycol & 1.53 & $\begin{array}{l}\text { Triethyleneglycol bis(2- } \\
\text { ethyl hexanoate) }\end{array}$ & 2.18 \\
\hline Hypermer KD-1 & 1.27 & Hypermer KD-1 & 1.24 & Hypermer KD-1 & 0.62 \\
\hline
\end{tabular}


Fig 1 Schematic of experimental set-up; (a) in-situ observation, (b) sample for free sintering, and (c) sample for vertical sintering $408 \times 288 \mathrm{~mm}(96 \times 96 \mathrm{DPI})$ 
Fig 1 Schematic of experimental set-up; (a) in-situ observation, (b) sample for free sintering, and (c) sample for vertical sintering $315 \times 265 \mathrm{~mm}$ (96 x 96 DPI) 
Fig 1 Schematic of experimental set-up; (a) in-situ observation, (b) sample for free sintering, and (c) sample for vertical sintering $333 \times 299 \mathrm{~mm}(96 \times 96 \mathrm{DPI})$ 


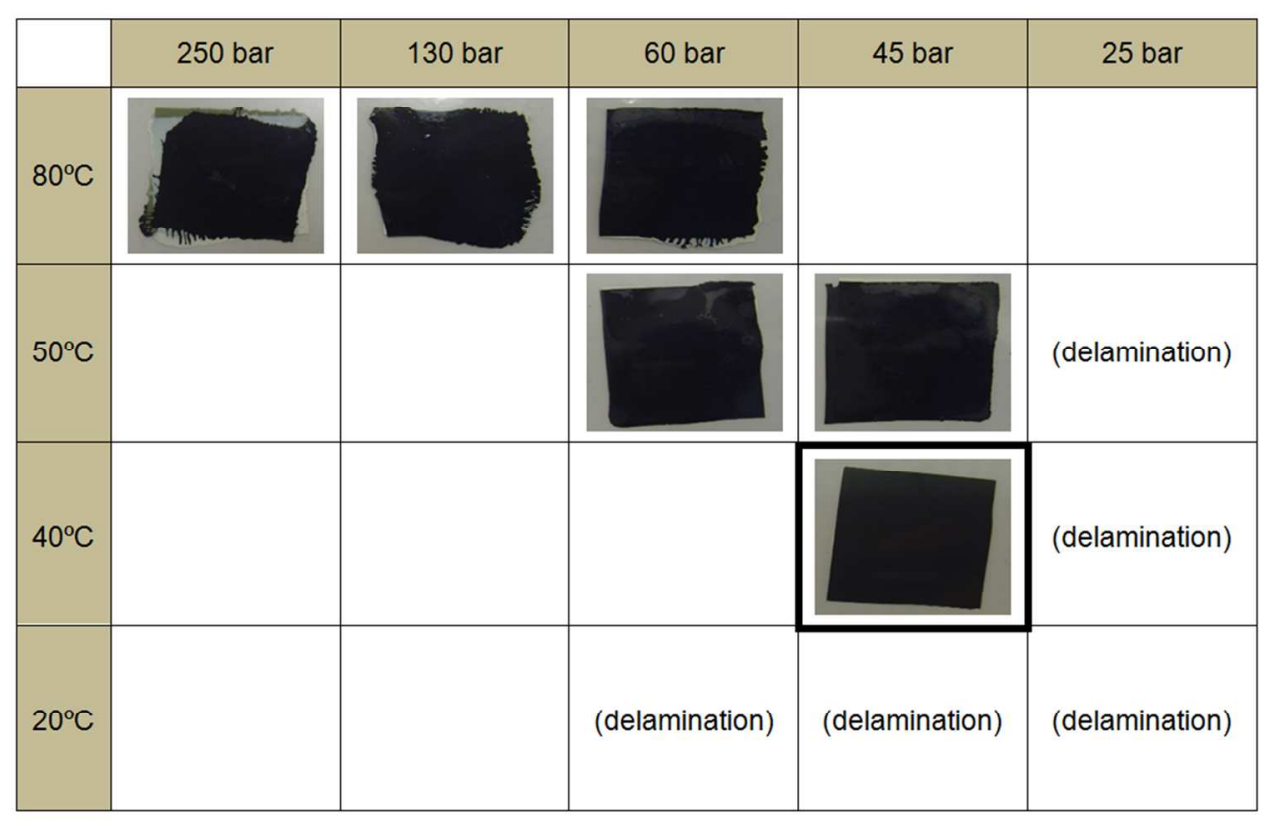

Fig 2 Multi-layer structures by hot pressing method under various lamination pressures (unit: bar) $714 \times 464 \mathrm{~mm}(96 \times 96 \mathrm{DPI})$ 
Fig 3 Shrinkage and shrinkage rate difference; (a) NiO/CGO, (b) CGO, (c) LSCF, and (d) shrinkage rate difference $277 \times 172 \mathrm{~mm}(96 \times 96 \mathrm{DPI})$

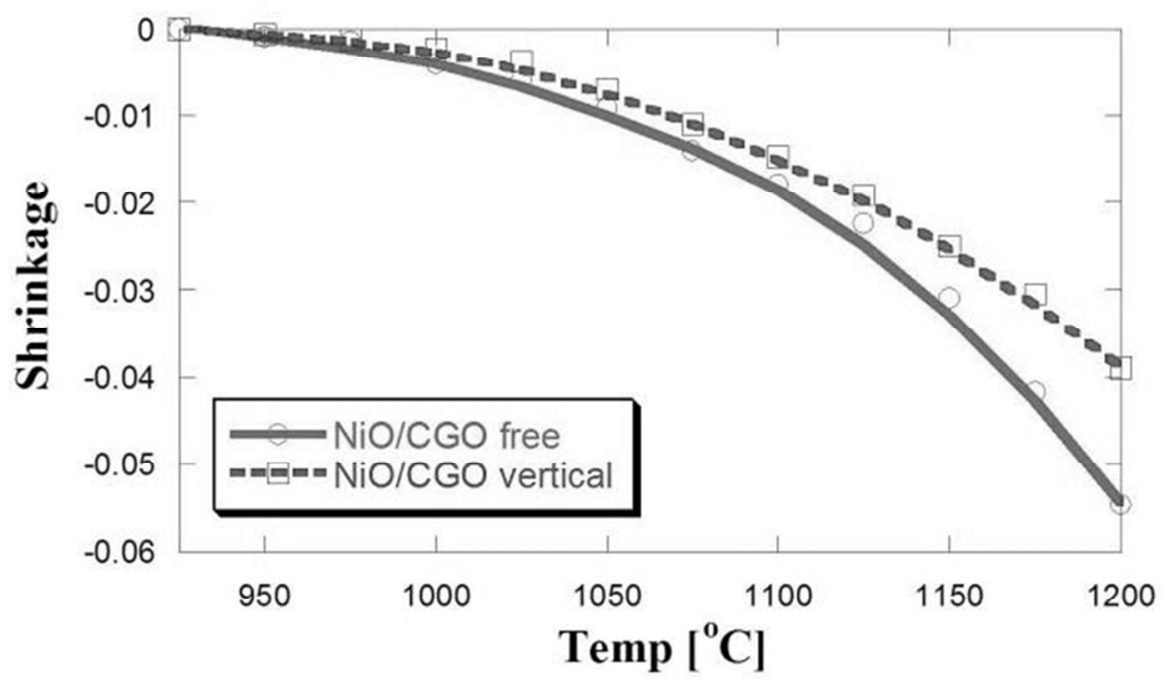


1

2

3

4

5

6

7

8

9

10

11

12

13

14

15

16

17

18

19

20

21

22

23

24

25

26

27

28

29

30

31

32

33

34

35

36

37

38

39

40

41

42

43

44

45

46

47

48

49

50

51

52

53

54

55

56

57

58

59

60

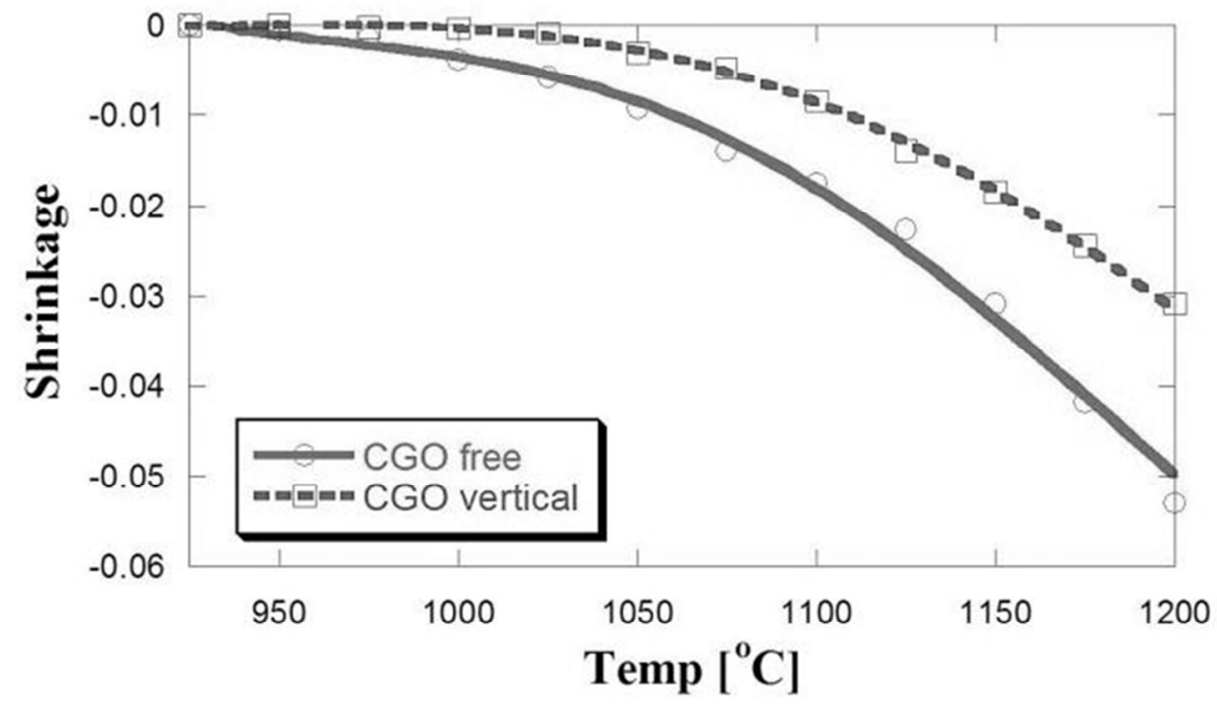

Fig 3 Shrinkage and shrinkage rate difference; (a) NiO/CGO, (b) CGO, (c) LSCF, and (d) shrinkage rate difference

$265 \times 166 \mathrm{~mm}(96 \times 96$ DPI) 


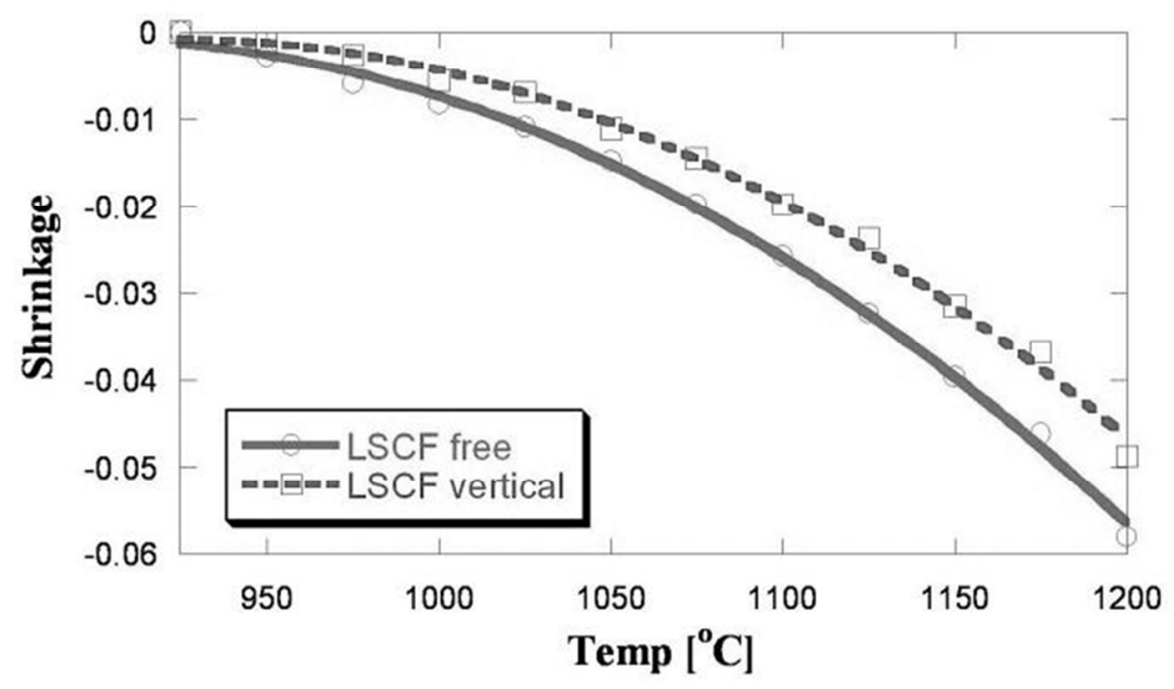

Fig 3 Shrinkage and shrinkage rate difference; (a) NiO/CGO, (b) CGO, (c) LSCF, and (d) shrinkage rate difference $276 \times 174 \mathrm{~mm}(96 \times 96 \mathrm{DPI})$ 
1

2

3

4

5

6

7

8

10

11

12

13

14

15

16

17

18

19

20

21

22

23

24

25

26

27

28

29

30

31

32

33

34

35

36

37

38

39

40

41

42

43

44

45

46

47

48

49

50

51

52

53

54

55

56

57

58

59

60

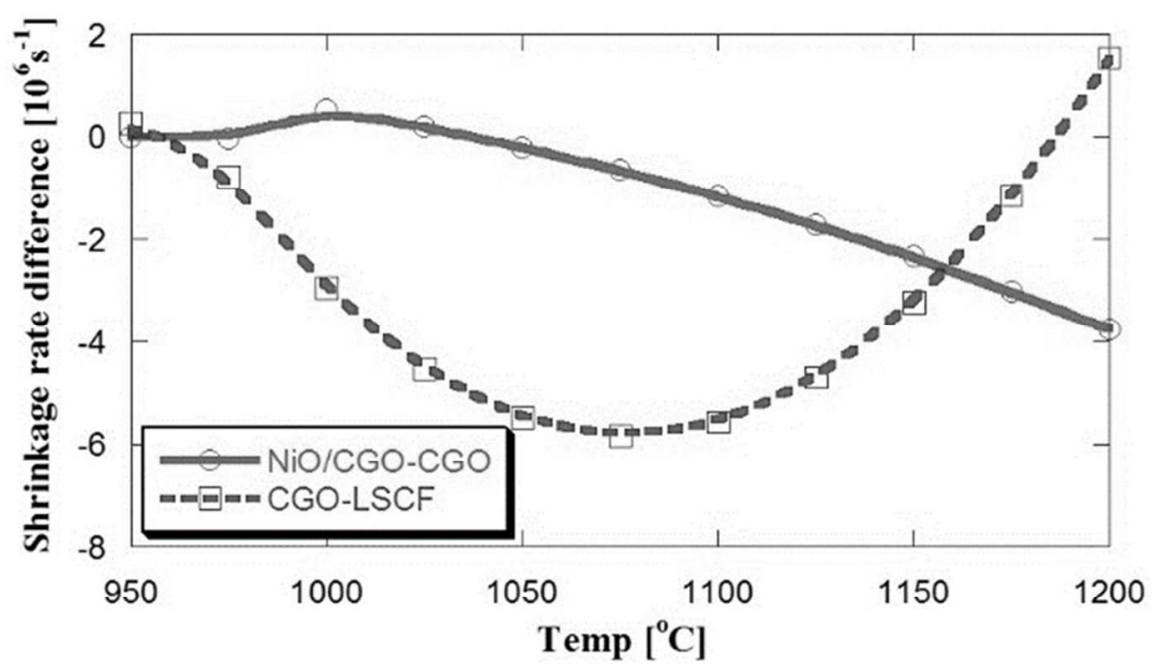

Fig 3 Shrinkage and shrinkage rate difference; (a) NiO/CGO, (b) CGO, (c) LSCF, and (d) shrinkage rate difference $273 \times 171 \mathrm{~mm}(96 \times 96 \mathrm{DPI})$ 


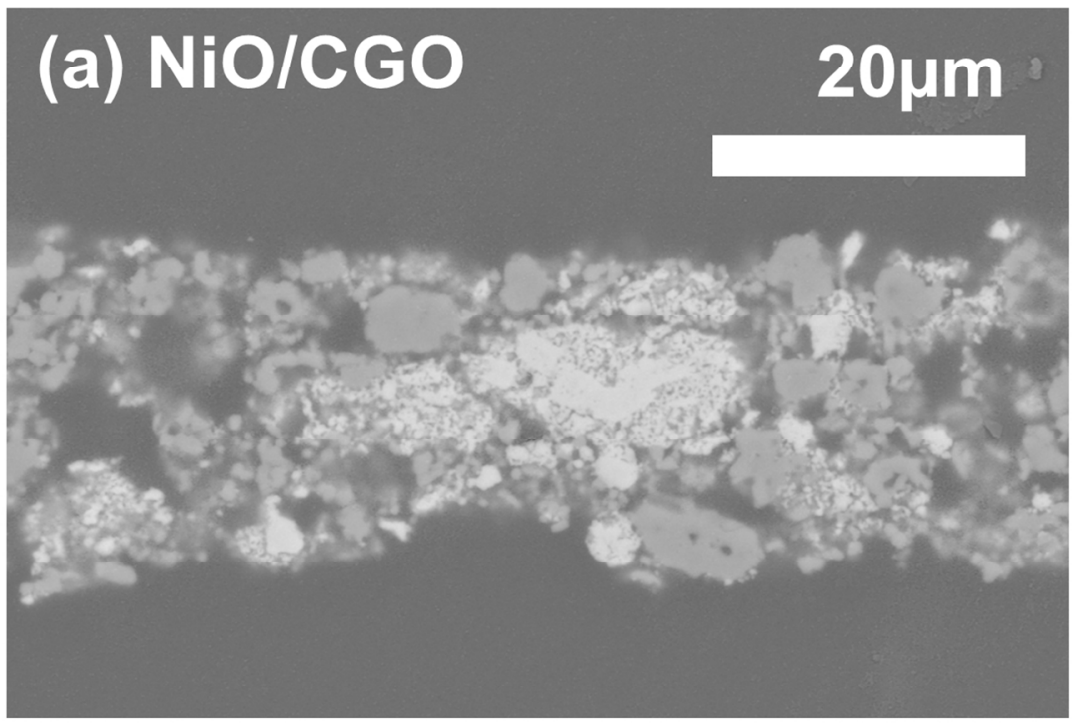

Fig 4 SEM images of each layer after the sintering process at $1200^{\circ} \mathrm{C}$ $388 \times 258 \mathrm{~mm}(96 \times 96 \mathrm{DPI})$ 


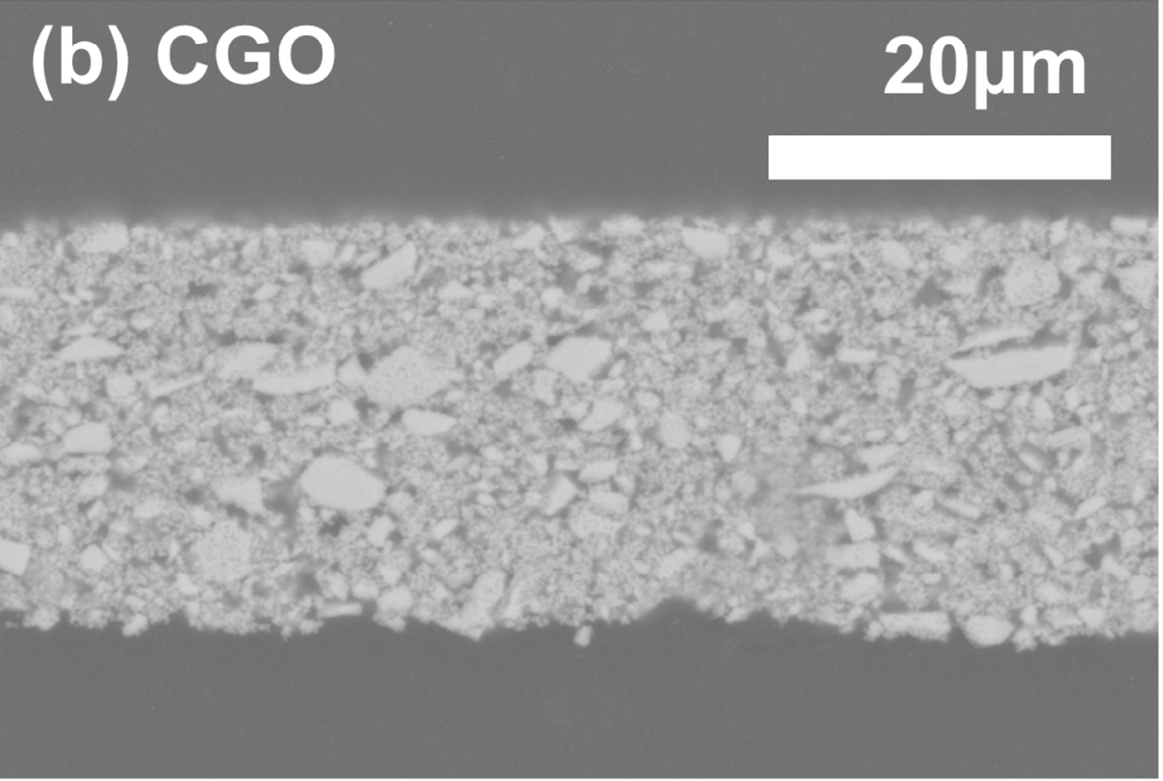

Fig 4 SEM images of each layer after the sintering process at $1200^{\circ} \mathrm{C}$ $355 \times 252 \mathrm{~mm}(96 \times 96 \mathrm{DPI})$ 


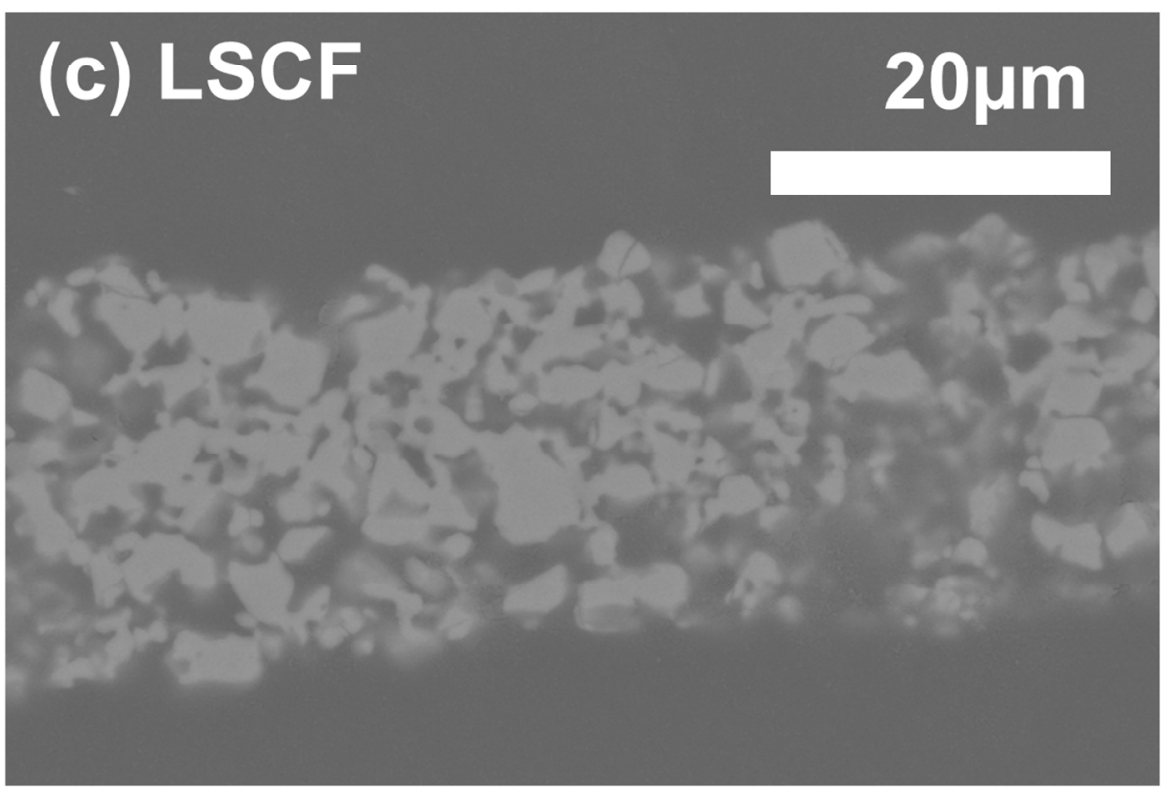

Fig 4 SEM images of each layer after the sintering process at $1200^{\circ} \mathrm{C}$ $357 \times 248 \mathrm{~mm}(96 \times 96$ DPI) 
Fig 5 Uniaxial viscosity: (a) NiO/CGO, (b) CGO, and (c) LSCF $366 \times 248 \mathrm{~mm}$ ( $96 \times 96$ DPI) 


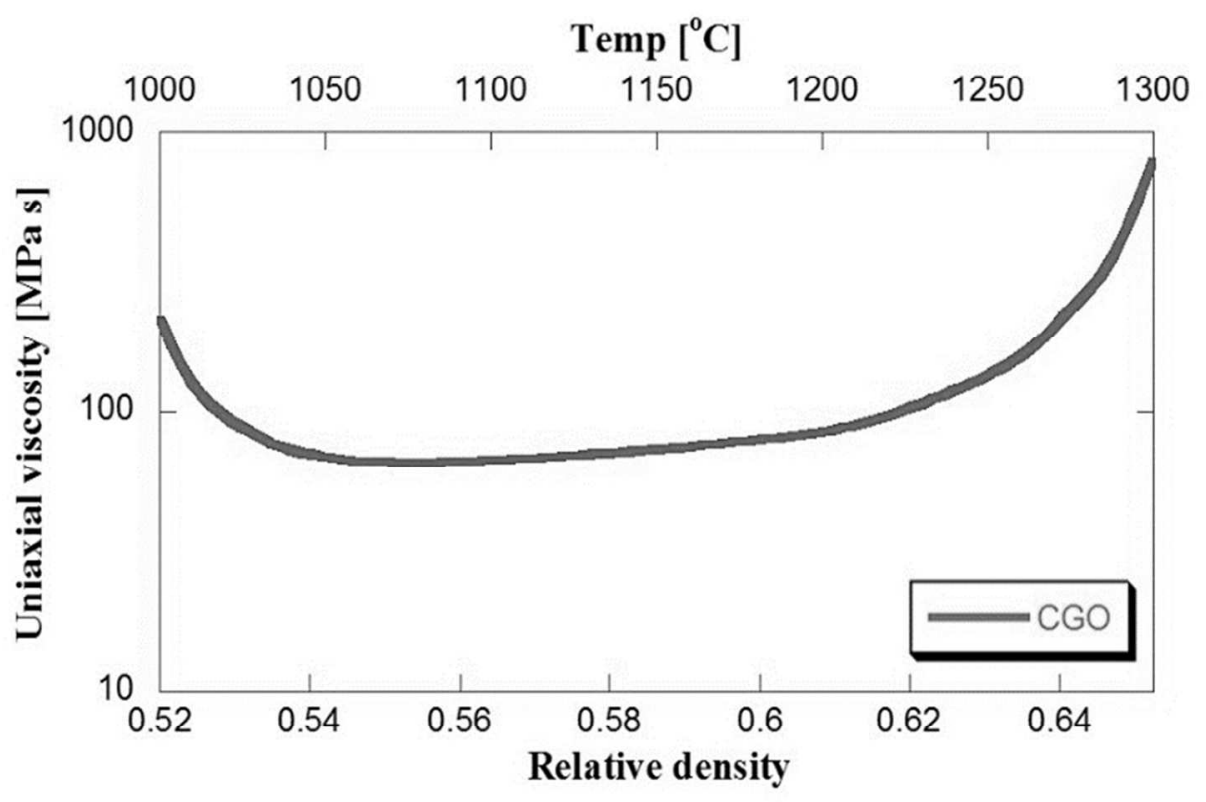

Fig 5 Uniaxial viscosity: (a) NiO/CGO, (b) CGO, and (c) LSCF $353 \times 245 \mathrm{~mm}(96 \times 96$ DPI) 
Fig 5 Uniaxial viscosity: (a) NiO/CGO, (b) CGO, and (c) LSCF $477 \times 306 \mathrm{~mm}(96 \times 96$ DPI) 


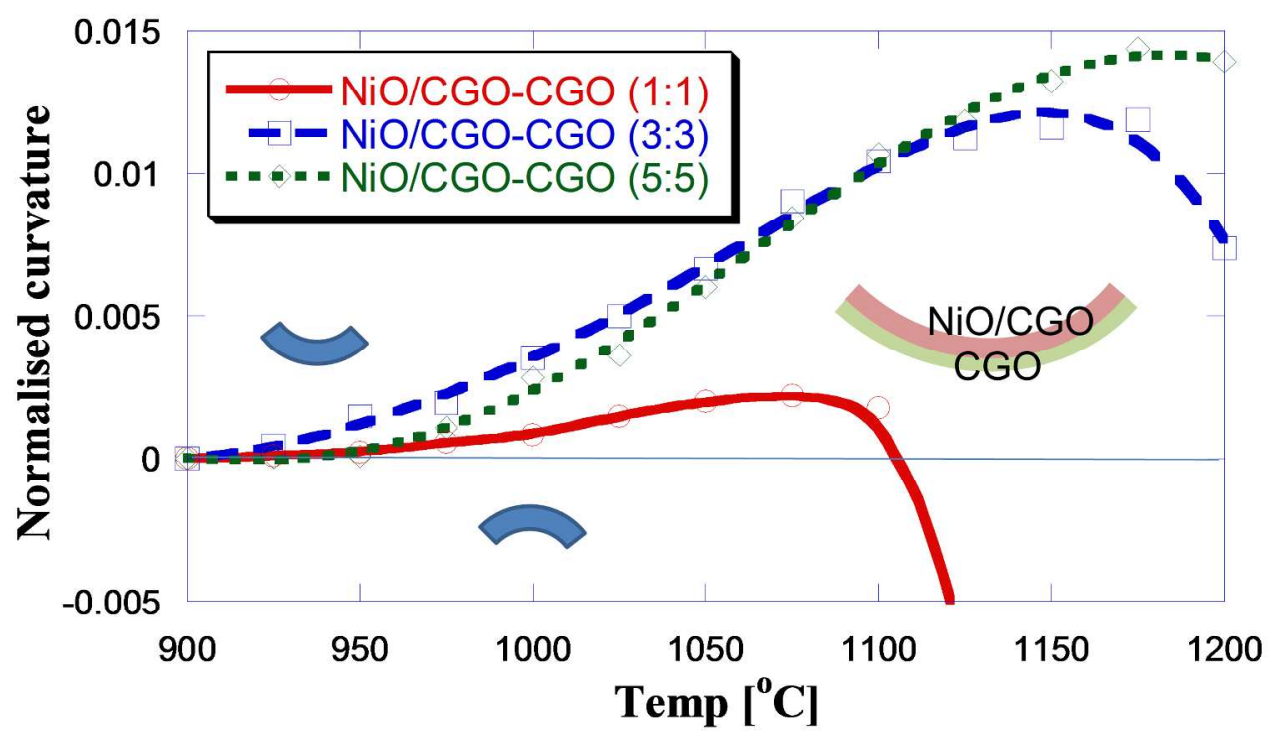

Fig 6 Normalised curvature of bi-layer structure: (a) NiO/CGO-CGO, (b) CGO-LSCF $692 \times 414 \mathrm{~mm}(96 \times 96 \mathrm{DPI})$ 


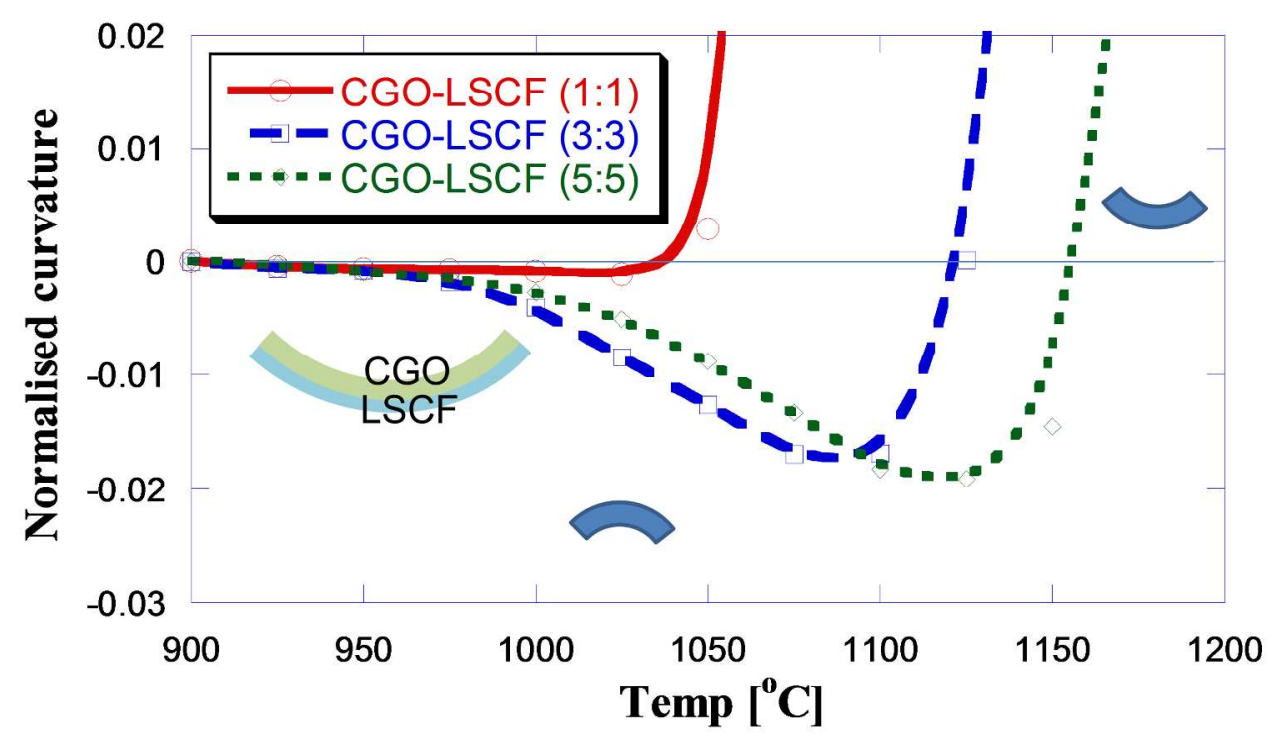

Fig 6 Normalised curvature of bi-layer structure: (a) NiO/CGO-CGO, (b) CGO-LSCF $706 \times 427 \mathrm{~mm}$ (96 x 96 DPI) 


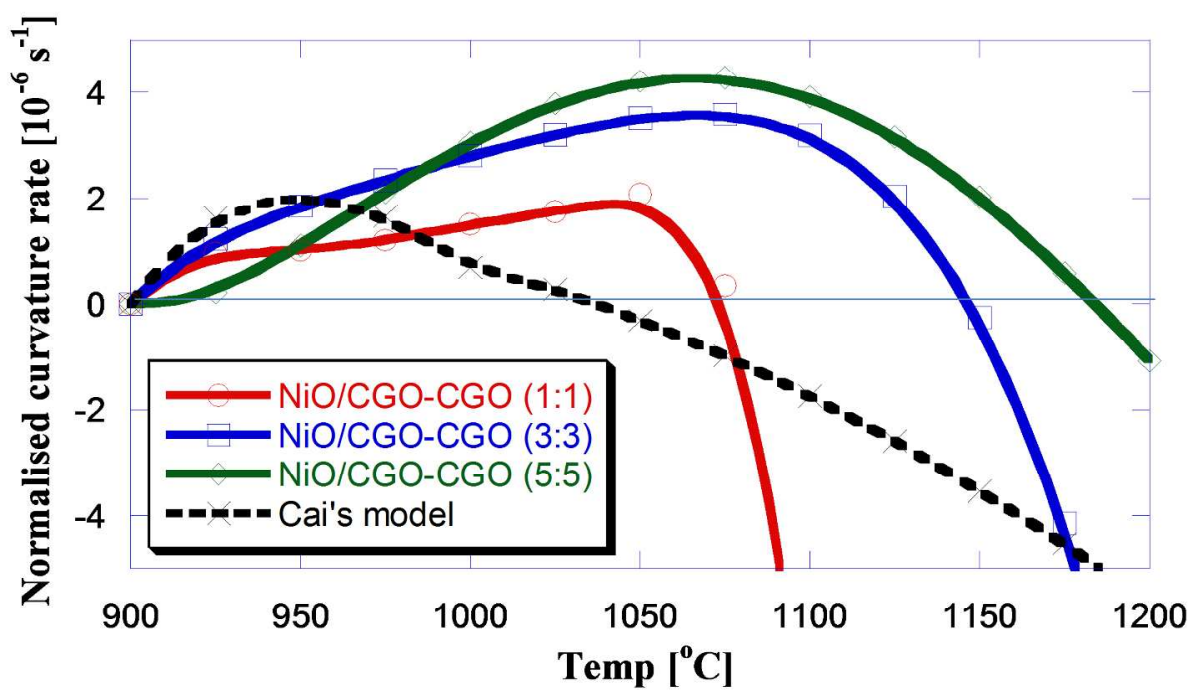

Fig 7 Normalised curvature rate; (a) NiO/CGO-CGO, (b) CGO-LSCF $670 \times 414 \mathrm{~mm}(96 \times 96 \mathrm{DPI})$ 


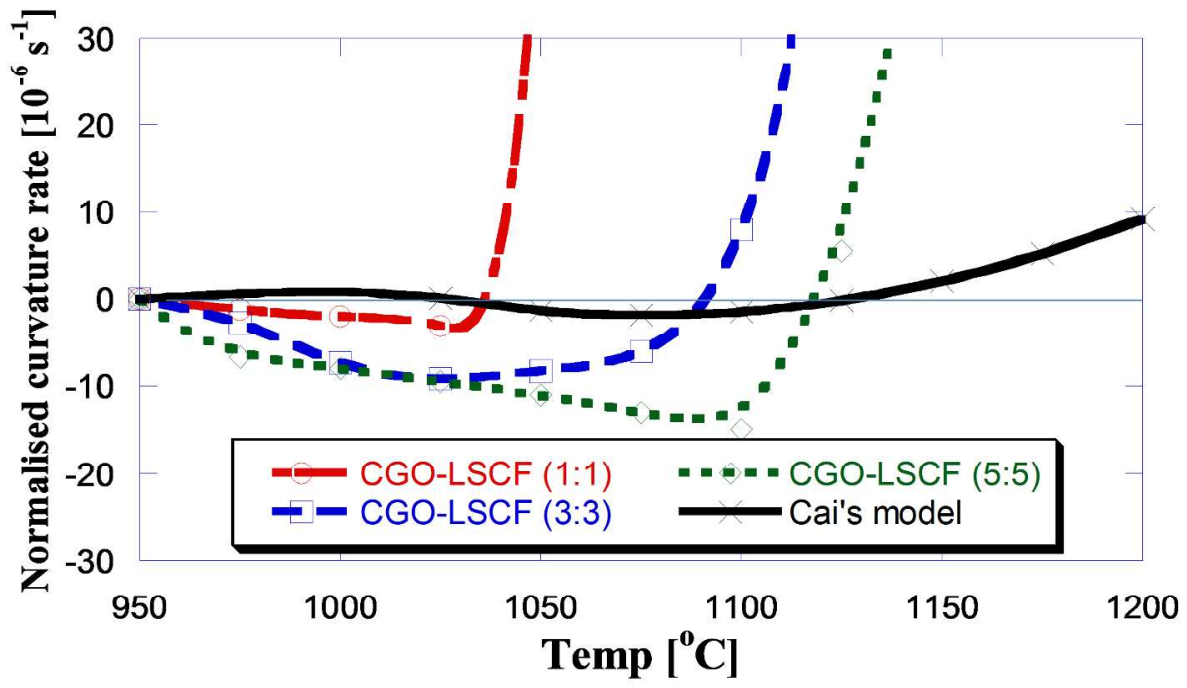

Fig 7 Normalised curvature rate; (a) NiO/CGO-CGO, (b) CGO-LSCF $699 \times 423 \mathrm{~mm}(96 \times 96 \mathrm{DPI})$ 


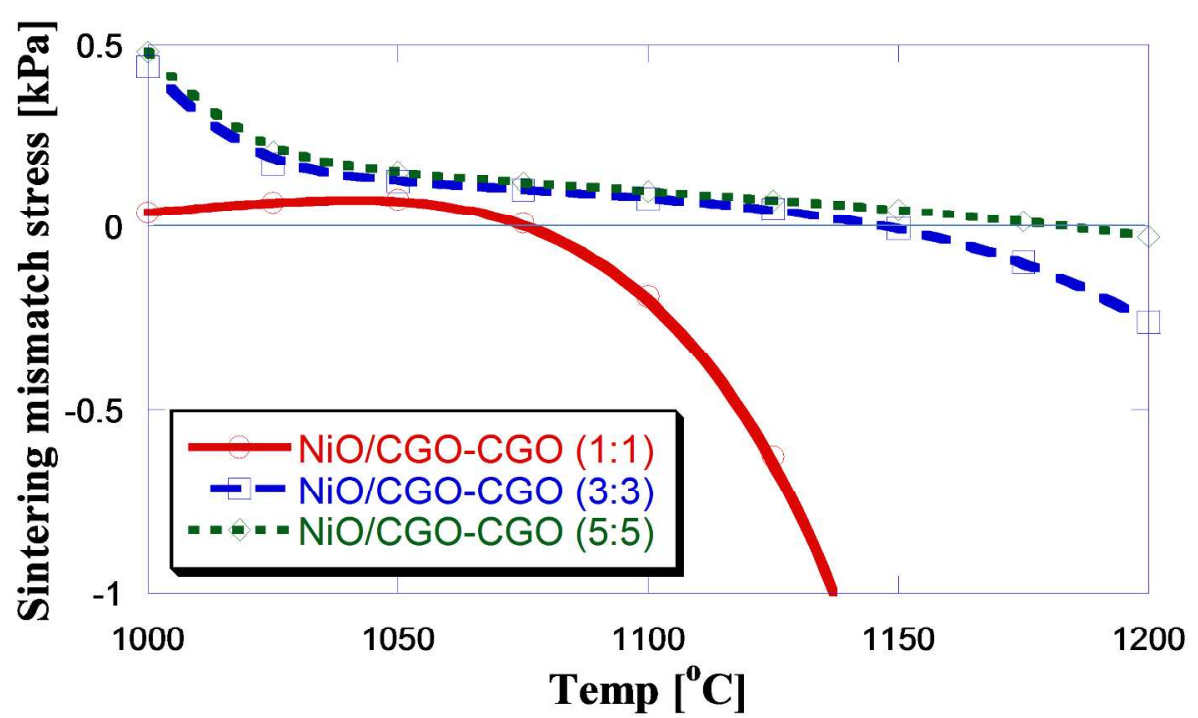

Fig 8 Sintering mismatch stress of bi-layer structure: (a) NiO/CGO-CGO, (b) CGO-LSCF $689 \times 437 \mathrm{~mm}(96 \times 96 \mathrm{DPI})$ 


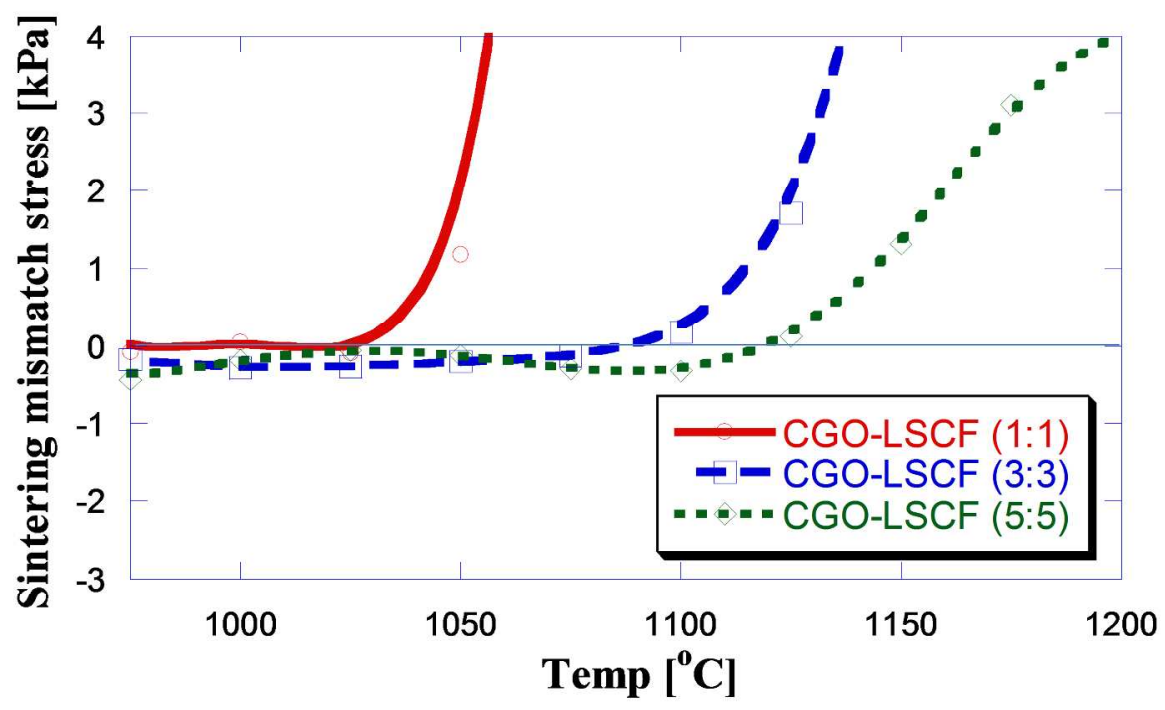

Fig 8 Sintering mismatch stress of bi-layer structure: (a) NiO/CGO-CGO, (b) CGO-LSCF $695 \times 433 \mathrm{~mm}(96 \times 96 \mathrm{DPI})$ 


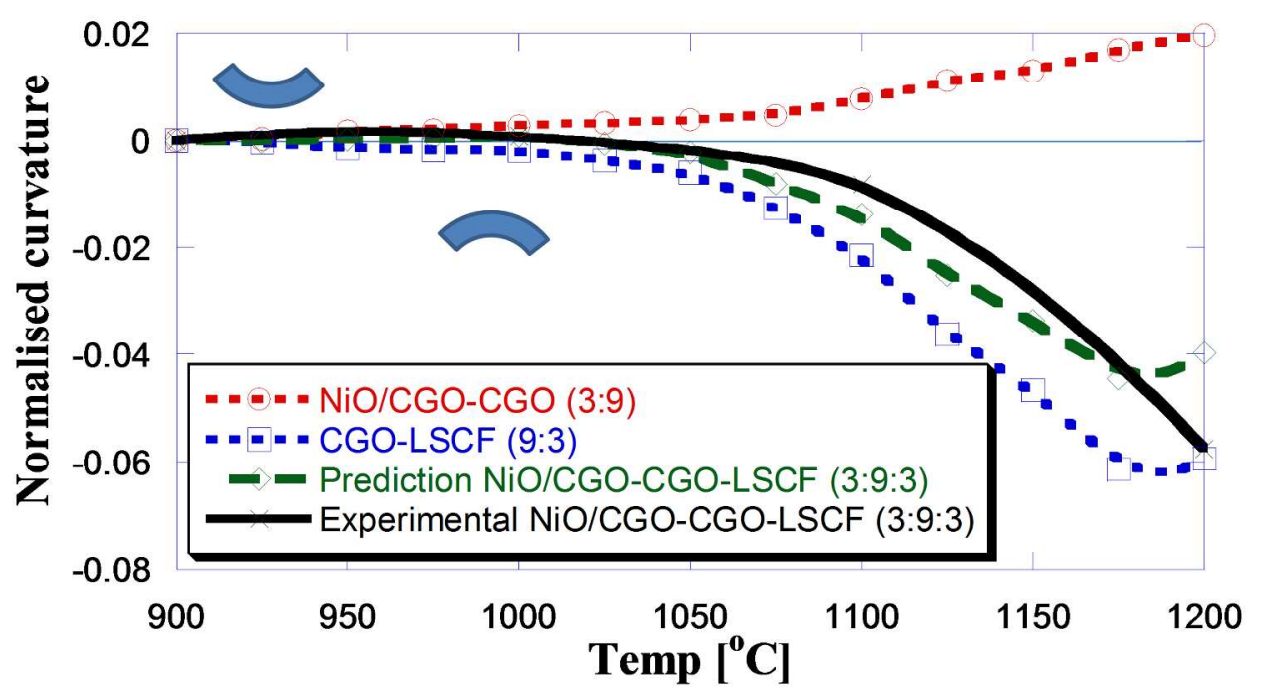

Fig 9 Curvature evolution of the triple-layer structures and prediction based on bi-layer structures $671 \times 393 \mathrm{~mm}(96 \times 96 \mathrm{DPI})$ 


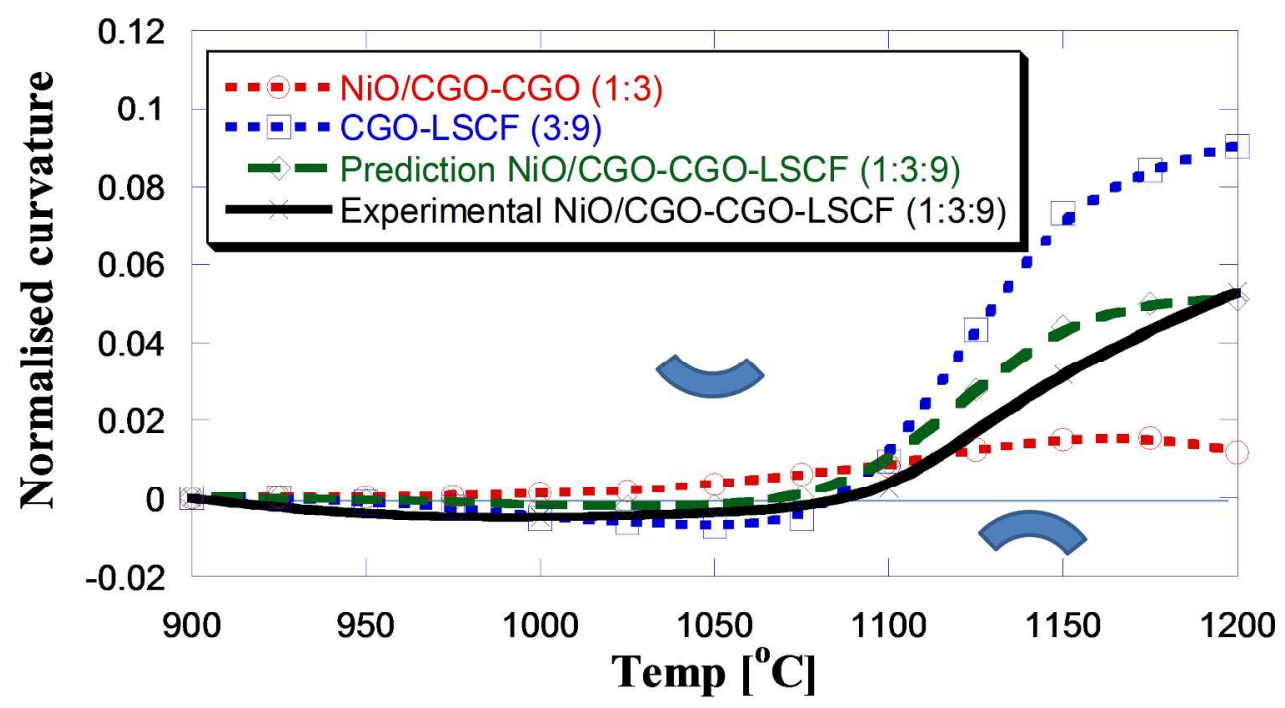

Fig 9 Curvature evolution of the triple-layer structures and prediction based on bi-layer structures $688 \times 393 \mathrm{~mm}(96 \times 96 \mathrm{DPI})$ 


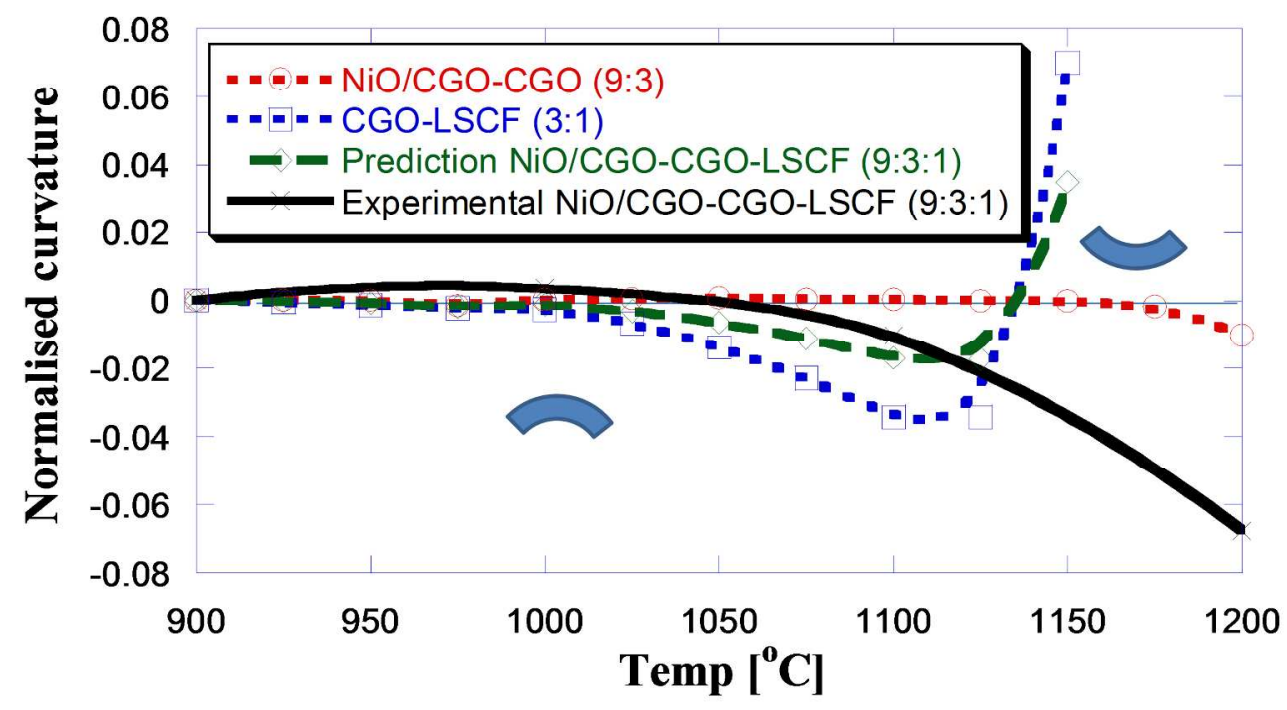

Fig 9 Curvature evolution of the triple-layer structures and prediction based on bi-layer structures $697 \times 405 \mathrm{~mm}(96 \times 96 \mathrm{DPI})$ 


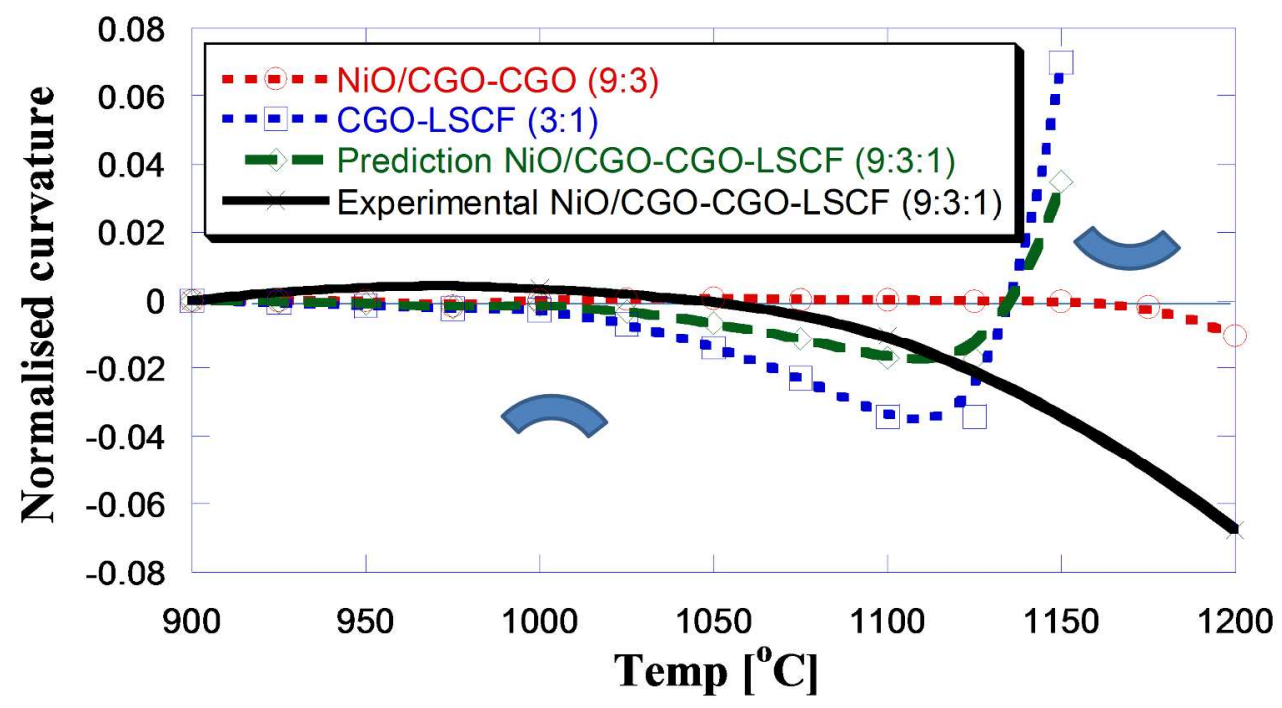

Fig 9 Curvature evolution of the triple-layer structures and prediction based on bi-layer structures $698 \times 391 \mathrm{~mm}(96 \times 96 \mathrm{DPI})$ 


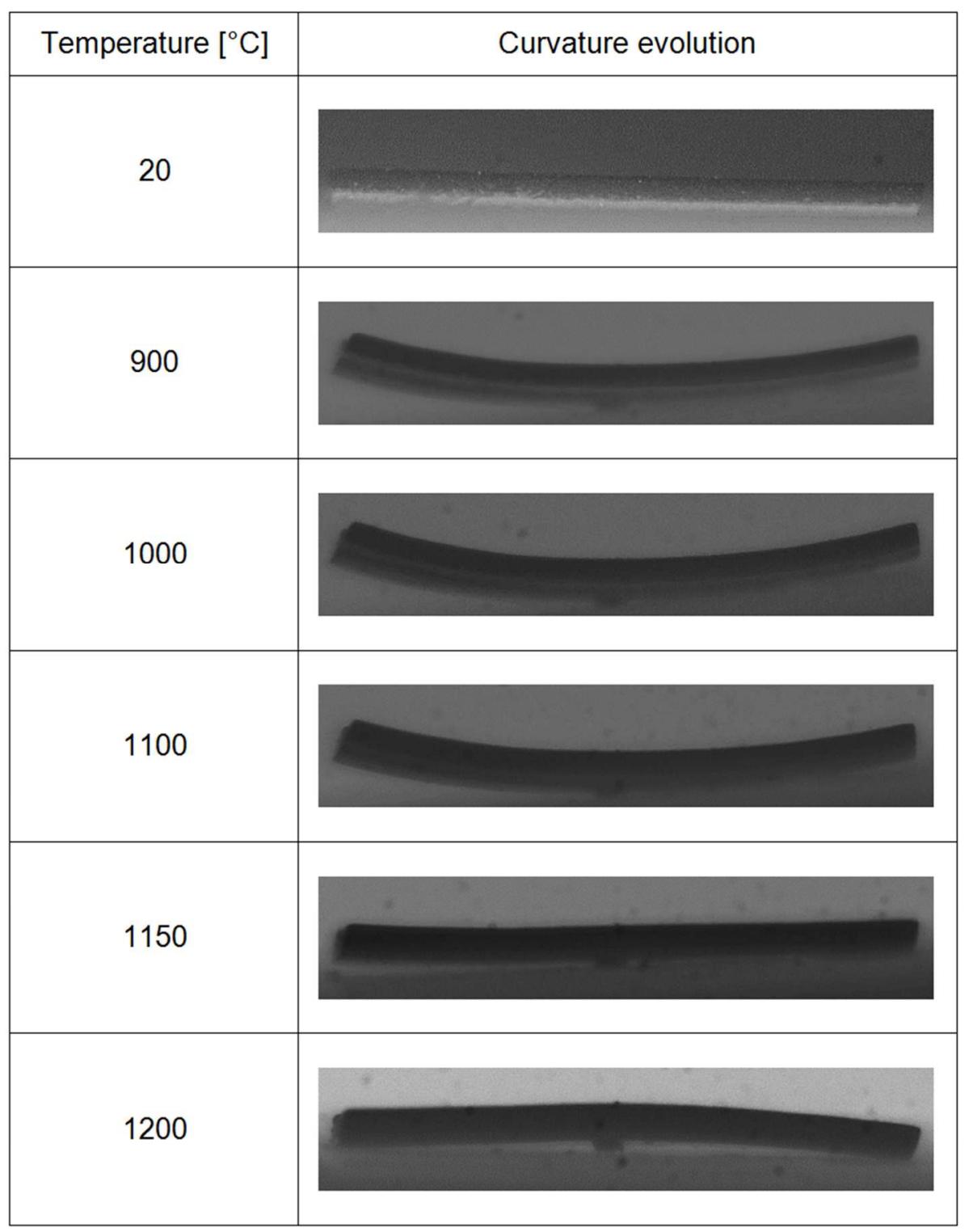

Fig 10 Experimental observation of curvature evolution in the triple-layer structure, consisting of 1 layer for $\mathrm{NiO} / \mathrm{CGO}$ (bottom), 3 layers for CGO, and 9 layers for LSCF (top). $452 \times 556 \mathrm{~mm}(96 \times 96 \mathrm{DPI})$ 
Fig 11 A wavy SC-SOFC fabrication process (a) (c), and SEM images; (a) initial set-up at $20^{\circ} \mathrm{C}$, (b) wavy shaping at $80^{\circ} \mathrm{C}$ during binder softening, (c) a wavy SC-SOFC after co-sintering, (d) (f) cross sections of the wavy structure, $(\mathrm{g})$ cross section of a planar structure, $(\mathrm{h}, \mathrm{i})$ at interfaces of the wavy structure.

$302 \times 232 \mathrm{~mm}(96 \times 96$ DPI) 
Fig 11 A wavy SC-SOFC fabrication process (a) (c), and SEM images; (a) initial set-up at $20^{\circ} \mathrm{C}$, (b) wavy shaping at $80^{\circ} \mathrm{C}$ during binder softening, (c) a wavy SC-SOFC after co-sintering, (d) $\sim(f)$ cross sections of the wavy structure, $(\mathrm{g})$ cross section of a planar structure, $(\mathrm{h}, \mathrm{i})$ at interfaces of the wavy structure.

$317 \times 236 \mathrm{~mm}(96 \times 96 \mathrm{DPI})$ 
Fig 11 A wavy SC-SOFC fabrication process (a) (c), and SEM images; (a) initial set-up at $20^{\circ} \mathrm{C}$, (b) wavy shaping at $80^{\circ} \mathrm{C}$ during binder softening, (c) a wavy SC-SOFC after co-sintering, (d) (f) cross sections of the wavy structure, $(\mathrm{g})$ cross section of a planar structure, $(\mathrm{h}, \mathrm{i})$ at interfaces of the wavy structure.

$309 \times 236 \mathrm{~mm}(96 \times 96 \mathrm{DPI})$ 


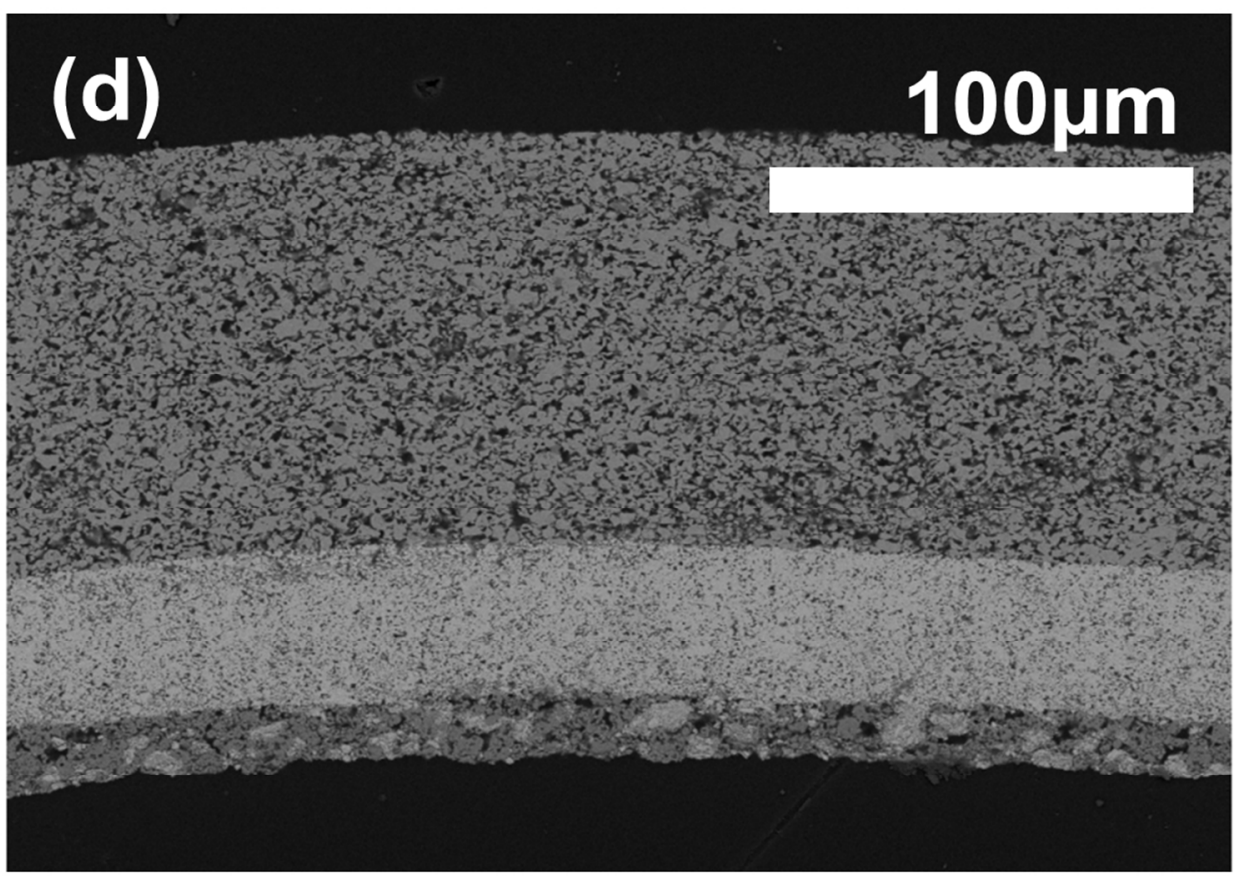

Fig 11 A wavy SC-SOFC fabrication process (a) (c), and SEM images; (a) initial set-up at $20^{\circ} \mathrm{C}$, (b) wavy shaping at $80^{\circ} \mathrm{C}$ during binder softening, (c) a wavy SC-SOFC after co-sintering, (d) $\sim$ (f) cross sections of the wavy structure, $(g)$ cross section of a planar structure, $(h, i)$ at interfaces of the wavy structure. $321 \times 231 \mathrm{~mm}(96 \times 96 \mathrm{DPI})$ 


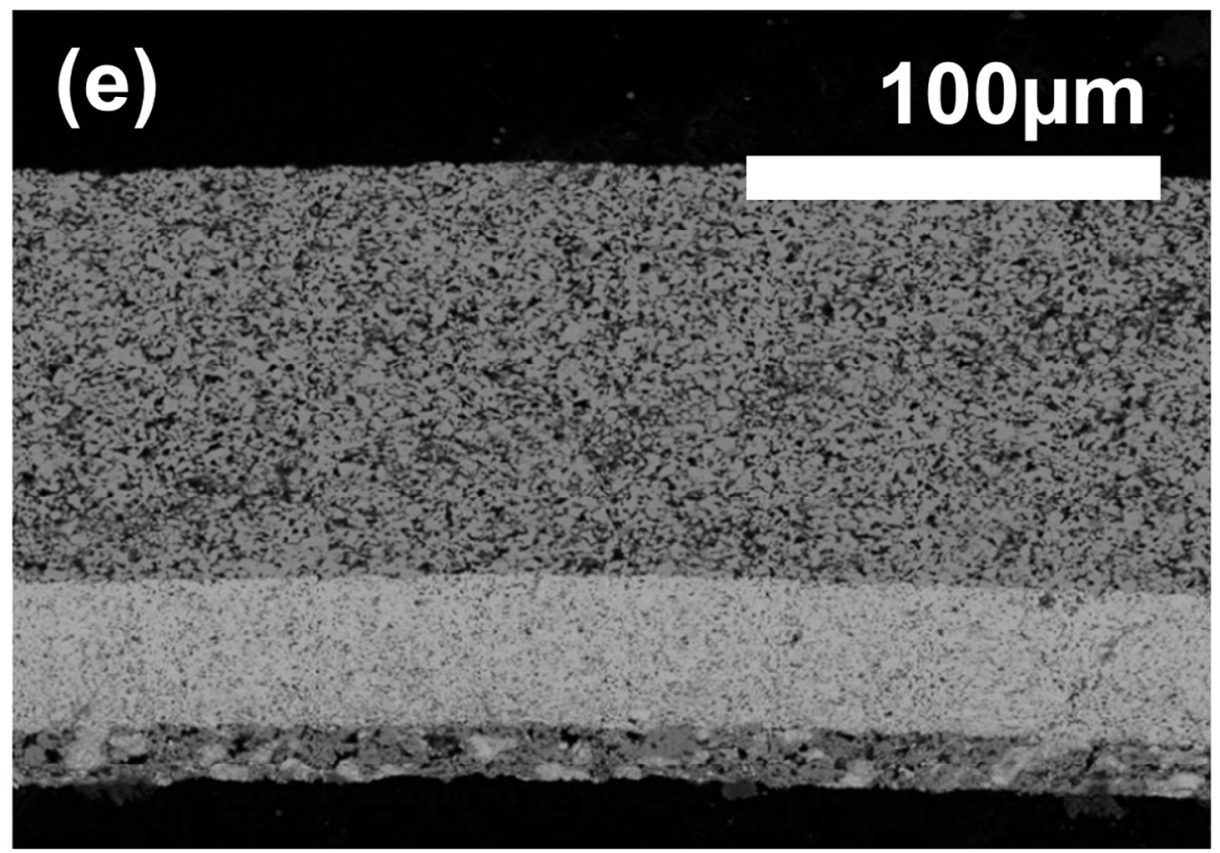

Fig 11 A wavy SC-SOFC fabrication process (a) (c), and SEM images; (a) initial set-up at $20^{\circ} \mathrm{C}$, (b) wavy shaping at $80^{\circ} \mathrm{C}$ during binder softening, (c) a wavy SC-SOFC after co-sintering, (d) (f) cross sections of the wavy structure, $(g)$ cross section of a planar structure, $(h, i)$ at interfaces of the wavy structure. $329 \times 236 \mathrm{~mm}(96 \times 96 \mathrm{DPI})$ 


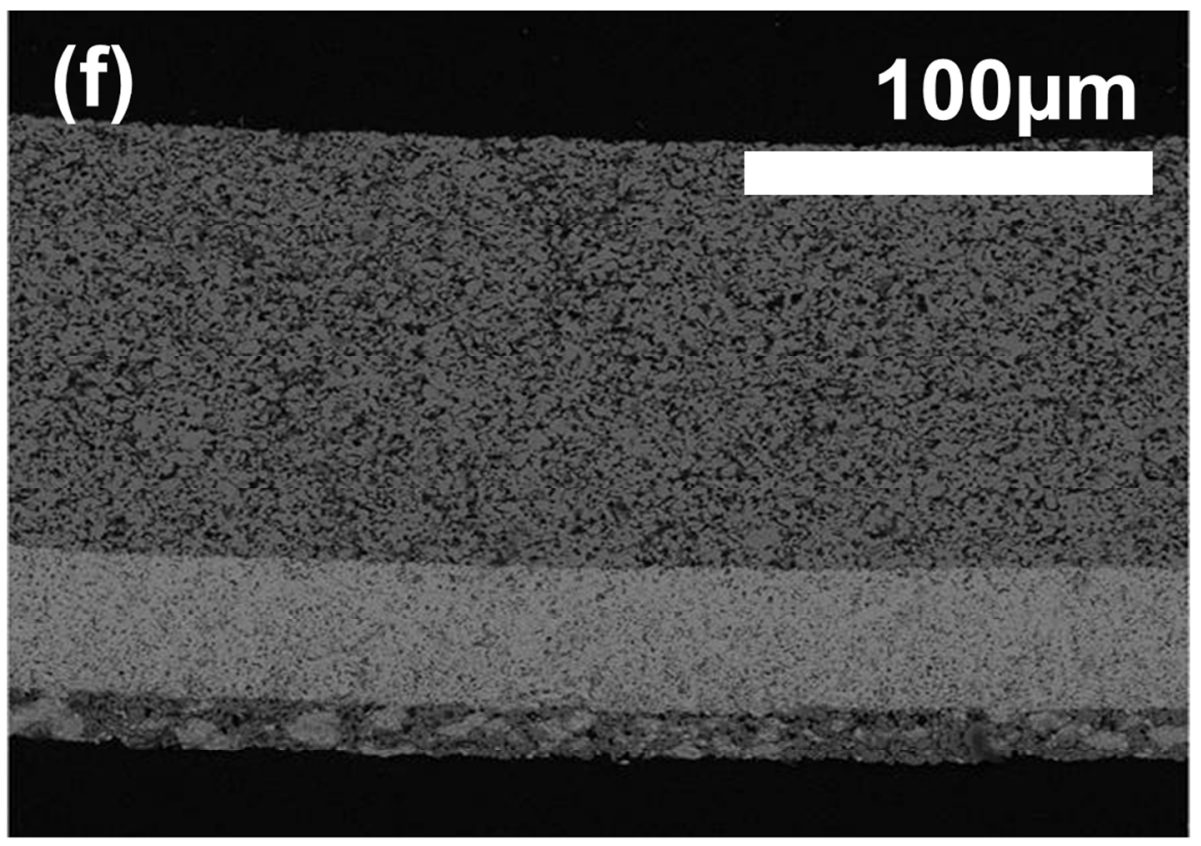

Fig 11 A wavy SC-SOFC fabrication process (a) (c), and SEM images; (a) initial set-up at $20^{\circ} \mathrm{C}$, (b) wavy shaping at $80^{\circ} \mathrm{C}$ during binder softening, (c) a wavy SC-SOFC after co-sintering, (d) $\sim$ (f) cross sections of the wavy structure, $(\mathrm{g})$ cross section of a planar structure, $(\mathrm{h}, \mathrm{i})$ at interfaces of the wavy structure. $334 \times 235 \mathrm{~mm}(96 \times 96 \mathrm{DPI})$ 
Fig 11 A wavy SC-SOFC fabrication process (a) (c), and SEM images; (a) initial set-up at $20^{\circ} \mathrm{C}$, (b) wavy shaping at $80^{\circ} \mathrm{C}$ during binder softening, (c) a wavy SC-SOFC after co-sintering, (d) (f) cross sections of the wavy structure, $(\mathrm{g})$ cross section of a planar structure, $(\mathrm{h}, \mathrm{i})$ at interfaces of the wavy structure. $347 \times 234 \mathrm{~mm}(96 \times 96 \mathrm{DPI})$ 


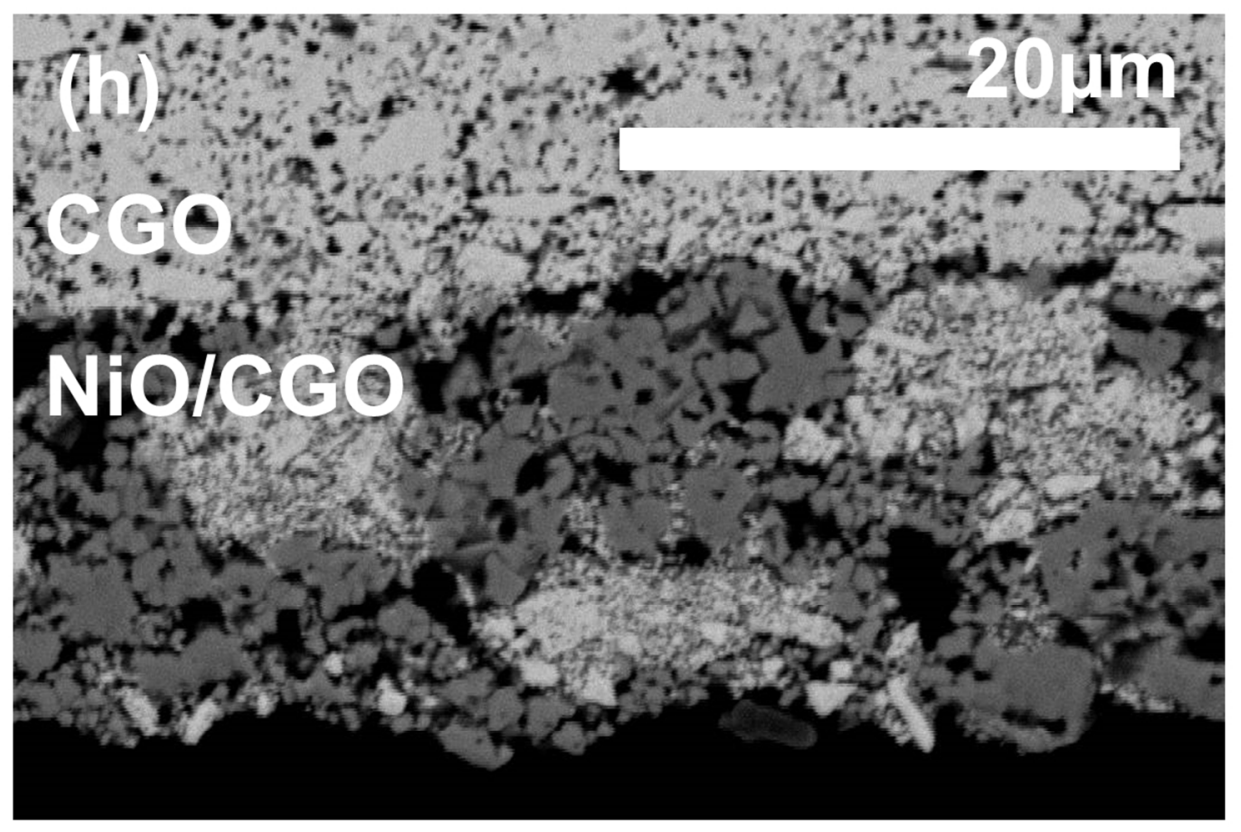

Fig 11 A wavy SC-SOFC fabrication process (a) (c), and SEM images; (a) initial set-up at $20^{\circ} \mathrm{C}$, (b) wavy shaping at $80^{\circ} \mathrm{C}$ during binder softening, (c) a wavy SC-SOFC after co-sintering, (d) (f) cross sections of the wavy structure, $(\mathrm{g})$ cross section of a planar structure, $(\mathrm{h}, \mathrm{i})$ at interfaces of the wavy structure. $342 \times 232 \mathrm{~mm}(96 \times 96 \mathrm{DPI})$ 
Fig 11 A wavy SC-SOFC fabrication process (a) (c), and SEM images; (a) initial set-up at $20^{\circ} \mathrm{C}$, (b) wavy shaping at $80^{\circ} \mathrm{C}$ during binder softening, (c) a wavy SC-SOFC after co-sintering, (d) $\sim(\mathrm{f})$ cross sections of the wavy structure, $(g)$ cross section of a planar structure, $(h, i)$ at interfaces of the wavy structure. $342 \times 239 \mathrm{~mm}$ (96 x 96 DPI) 


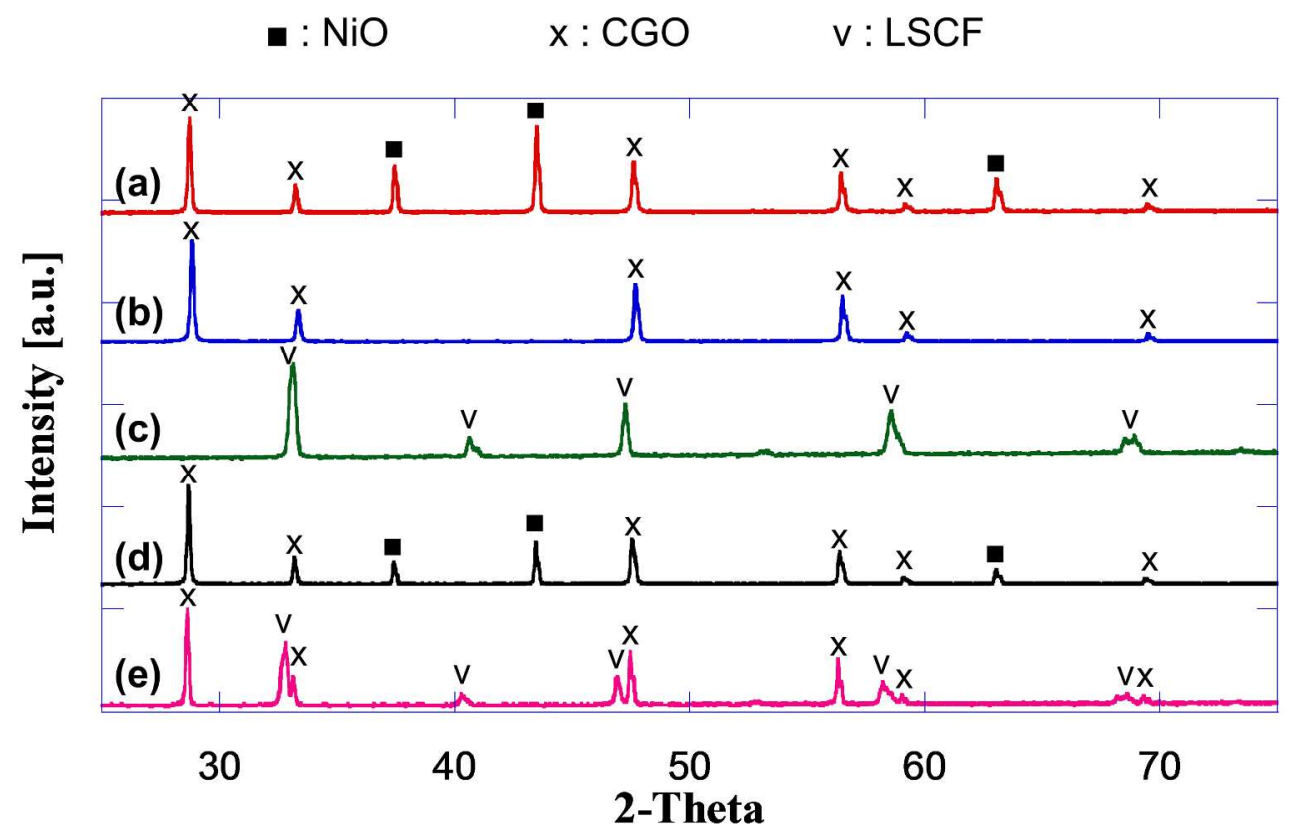

Fig 12 XRD result for third-phase formation of the wavy structure during co-sintering; (a) NiO/CGO, (b) CGO, (c) LSCF, (d) NiO/CGO-CGO, and (e) CGO-LSCF $729 \times 482 \mathrm{~mm}(96 \times 96 \mathrm{DPI})$ 